\title{
Advances in understanding of mycorrhizal-like associations in bryophytes
}

\author{
SILVIA PRESSEL ${ }^{1 *}$, MARTIN I. BIDARTONDO ${ }^{2}$, KATIE J. FIELD ${ }^{3} \&$ JEFFREY G. DUCKETT $^{1}$ \\ ${ }^{1}$ Life Sciences Department, The Natural History Museum, Cromwell Road, London SW7 5BD, UK; \\ झ"s.pressel@nhm.ac.uk; @ https://orcid.org/0000-0001-9652-6338 \\ ="j.g.duckett@qmul.ac.uk; @ https://orcid.org/0000-0001-7101-6673 \\ ${ }^{2}$ Imperial College London and Royal Botanic Gardens, Kew TW9 3DS, UK;

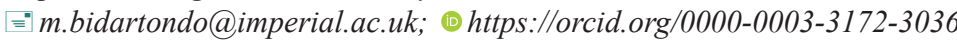 \\ ${ }^{3}$ Department of Animal and Plant Sciences, University of Sheffield, Sheffield, S10 2TN, UK,

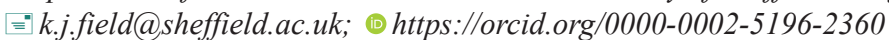 \\ * Corresponding author
}

\begin{abstract}
Mutually beneficial associations between plants and soil fungi, mycorrhizas, are one of the most important terrestrial symbioses. These partnerships are thought to have propelled plant terrestrialisation some 500 million years ago and today they play major roles in ecosystem functioning. It has long been known that bryophytes harbour, in their living tissues, fungal symbionts, recently identified as belonging to the three mycorrhizal fungal lineages Glomeromycotina, Ascomycota and Basidiomycota. Latest advances in understanding of fungal associations in bryophytes have been largely driven by the discovery, nearly a decade ago, that early divergent liverwort clades, including the most basal Haplomitriopsida, and some hornworts, engage with a wider repertoire of fungal symbionts than previously thought, including endogonaceous members of the ancient sub-phylum Mucoromycotina. Subsequent global molecular and cytological studies have revealed that Mucoromycotina symbionts, alongside Glomeromycotina, are widespread in both complex and simple thalloid liverworts and throughout hornworts, with physiological studies confirming that, in liverworts at least, these associations are mycorrhizallike, and highlighting important functional differences between Mucoromycotina and Glomeromycotina symbioses. Whether a more prominent role of Mucoromycotina symbionts in plant nitrogen nutrition, as identified in liverworts, extends to other plant lineages, including the flowering plants, is a major topic for future research.

The latest finding that ascomycete symbionts of leafy liverworts are not restricted to one fungus, Rhizoscyphus ericae, but include species in the genus Meliniomyces, as shown here in Mylia anomala, together with the recent demonstration that $R$. ericae forms nutritional mutualisms with the rhizoids of Cephalozia bicuspidata, fill other major gaps in our growing knowledge of fungal associations across land plants.
\end{abstract}

Key words: Endogonales, fungal associations, hornworts, liverworts, Meliniomyces, Mylia anomala

\section{Introduction}

It has been known for a very long time that many bryophytes, with the exclusion of mosses, harbour in their living tissues filamentous fungi, which produce a variety of structures comparable to those formed by mycorrhizal fungi in the roots of modern vascular plants (Read et al. 2000, Ligrone et al. 2007, Pressel et al. 2010) and indeed in the prostrate and aerial axes of ancient fossil plants (Remy et al. 1994, Taylor et al. 1995). From their discovery by Gottsche in 1843, for over a 120 years these were simply described and illustrated by line drawings from a wide range of liverworts (see review in Schuster 1966) but with their real nature remaining purely conjectural. Electron microscope studies then revealed diverse kinds of fungi in both liverworts and hornworts with the demonstration of healthy hyphae in heathy host cells indicating that the associations were likely mutualistic (see Ligrone 1988, Read et al. 2000, Ligrone et al. 2007 and literature therein). In contrast, possible mutualistic associations have yet to be detected in mosses. Although numerous fungi have been described from mosses, we are not aware of a single micrograph showing healthy hyphae and host cytoplasm in the same cell. The most likely explanation is that, with diameters down to $2 \mu \mathrm{m}$, the ultimate ramifications of multicellular moss rhizoids match the nutrient-scavenging capabilities of fungal hyphae (Field et al. $2015 \mathrm{~b}$ ) and thus preclude the evolution of nutritional symbiosis between mosses and fungi. 
More recently, molecular studies have confirmed the identity of the fungi inhabiting the rhizoids and/or thalli of liverworts and hornworts as members of the three major clades of mycorrhizal fungi Glomeromycotina, Ascomycota and Basidiomycota (Chambers et al. 1999, Ligrone et al. 2007, Upson et al. 2007, Pressel et al. 2008a, b, Bidartondo \& Duckett 2010, Newsham \& Bridge 2010, Preußing et al. 2010). Based exclusively on cytological evidence, but with no confirmation from physiological studies, bryophyte-fungal associations were assumed to represent, like their counterparts in vascular plants, mutually beneficial symbioses with bidirectional exchange of resources between partners, i.e. to be mycorrhizal-like given the absence of true roots in bryophytes. This situation has now changed radically since our last review on fungal associations in bryophytes a decade ago (Pressel et al. 2010). Another major recent advance in understanding of bryophyte fungal associations has been the discovery, hinted at in Pressel et al. (2010), that the fungal symbionts of the earliest diverging liverwort clade, Haplomitriopsida (Forrest et al. 2006), are not arbuscular mycorrhizal fungi in the Glomeromycotina, as previously assumed (Wang \& Qui 2006, Ligrone et al. 2007), but members of another major fungal clade, the Endogonales (Mucoromycotina), which has so far been little studied (Bidartondo et al. 2011, Bonfante \& Venice 2020). This crucial discovery was a catalyst for much increased interest in bryophyte-fungal associations during the last decade, with ongoing research aimed at elucidating the diversity and functional significance of these partnerships globally.

Studies of bryophyte-fungal symbioses have also provided powerful insights into the origin and evolution of mycorrhizal associations in land plants. Both fossil (Remy et al. 1994, Taylor et al. 1995, Krings et al. 2007, StrulluDerrien et al. 2014) and molecular evidence, the latter showing that the genes and biochemical pathways required for mycorrhization are conserved across all land plant lineages (Wang et al. 2010, Delaux et al. 2013, Oldroyd 2013) and that components of this symbiotic 'toolkit' are present within ancestral lineages of charophytic algae (Delaux et al. 2015), indicate that these associations are ancient and likely played a key role in the establishment and subsequent diversification of the land flora (Pirozynski \& Malloch 1975, Krings et al. 2012). Here we review advances in understanding of bryophyte fungal associations over the last decade and present novel observations on the distinctive fungal association in the leafy liverwort Mylia anomala (Hook.) Gray.

\section{Diversity of fungal associations in bryophytes}

\section{Liverworts}

The history of liverwort symbioses with fungi is one of losses, reacquisitions, jumps, and swaps, including symbioses that are common to both liverworts and vascular plants (Pressel et al. 2010, Rimington et al. 2018, 2020 and references therein). Until recently, symbioses with arbuscular mycorrhizal forming fungi in the Glomeromycotina (AMF), like those in pteridophytes and angiosperms, were considered to be ancestral in liverworts, based on their apparent occurrence in Haplomitriopsida at the base of the liverwort tree and definitively in both the Marchantiidae and the Pelliidae in the complex and simple thalloid lineages respectively (Ligrone et al. 2007, Crandall-Stotler et al. 2009a, b). These symbioses were in turn lost in later clades of the Jungermanniopsida (Crandall-Stotler et al. 2009a, b). Thereafter fungal symbionts were either basidiomycetes in the derived thalloid family Aneuraceae in the Metzgeriidae (Bidartondo \& Duckett 2010), but probably ascomycetes in the swollen rhizoids in the sister family Mizutaniaceae (Pressel et al. 2011), or, in the Jungermanniales, a mixture of either basidiomycetes (Arnelliaceae, Lophocoleaceae, Geocalycaeae, Scapaniaceae) or ascomycetes (Calypogeiaceae, Cephaloziaceae, Cephaloziellaceae, Lepidoziaceae, Eremonotus Lindb. \& Kaal. ex Pearson in the Jungermanniaceae and Geocalyx Nees in the Geocalycaeae) (Pressel et al. 2008a, b, Bidartondo \& Duckett 2010), with recent liverwort phylogenies indicating that the latter were first acquired in the rhizoids of the Schistochilaceae (Pressel et al. 2008a, b). In marked contrast Porellales, containing the most speciose liverwort family, Lejeuneaceae, are fungus-free, probably reflecting their high degree of epiphytism.

\section{Fungal associations in Marchantiopsida and Pelliidae}

The demonstration by Bidartondo et al. (2011) that Treubia K.I. Goebel and Haplomitrium Nees are consistently colonised by members of the Endogonales (Endogonaceae and Densosporaceae) in the subphylum Mucoromycotina and do not harbour Glomeromycotina AMF, has led to a major shift in understanding the diversity of fungal associations in liverworts and other plants. Since this discovery, made possible by technical advancements in the molecular detection of fungal symbionts, and through extensive global sampling, it has become apparent that associations with Mucoromycotina fungi are widespread in both complex and simple thalloids (Rimington et al. 2018, 2019, 2020). However, in these groups symbioses are not exclusive, with most liverwort species found to date to harbour Mucoromycotina fungi also able to host Glomeromycotina, sometimes with both fungi co-colonising the same host 


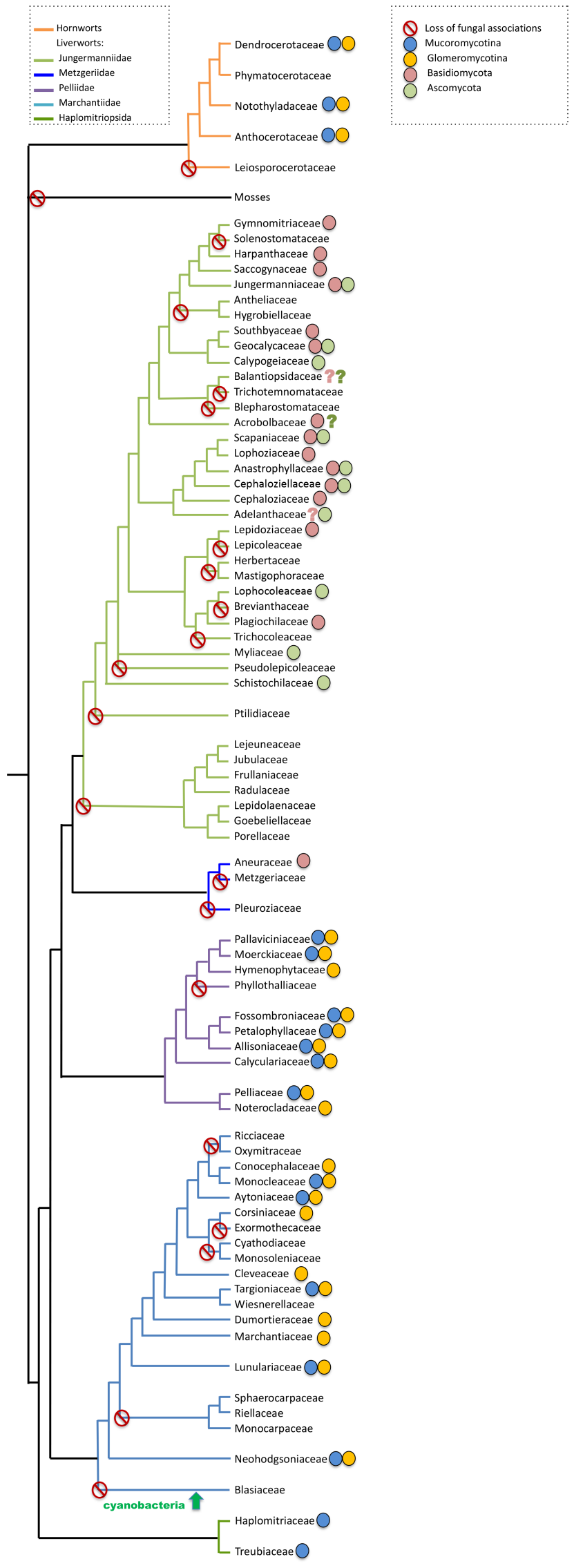

FIGURE 1. Phylogram showing the diversity and distribution of fungal assocations in bryophytes - adapted from Rimington et al. (2020). 
in dual symbiosis (Field et al. 2016, Rimington et al. 2020). This situation parallels that in hornworts (Desirò et al. 2013) and pteridophytes (Rimington et al. 2015, Pressel et al. 2016), with the only currently known exception being the lycophyte Lycopodiella inundata (L.) Holub which, after detailed sampling of several populations, appears to form partnerships, like Treubia and Haplomitrium, only with Mucoromycotina (Rimington et al. 2015, Hoysted et al. 2019, 2020, Kowal et al. 2020).

The taxonomic distribution of Mucoromycotina symbioses in liverworts (Fig. 1) indicates that they represent the ancestral type and were subsequently lost in Marchantiopsida during the divergence of the Blasiales (the only early divergent lineage that is fungus-free but forms symbioses with cyanobacteria; Adams \& Duggan 2008), and the Sphaerocarpales in the Marchantiidae, only to be regained elsewhere in the Marchantiidae, in the Neohodgsoniales, Lunulariales and several families in the Marchantiales, i.e. Marchantiaceae, Monocleaceae, Aytoniaceae and Targioniaceae. Absence of fungi in some marchantialean families (Monoseleniaceae, Cyathodiaceae, Exormothecaceae, Monocarpaceae, Oxymitraceae, Ricciaceae and probably Corsiniaceae and Wiesnerellaceae) is almost certainly a derived state. In Pelliidae, Mucoromycotina symbiosis has been maintained in Pellia Raddi, Calycularia Mitt., Allisonia Herzog, Fossombronia Raddi and Moerckia Gottsche, lost in Noteroclada Taylor ex Hook. \& Wilson, Petalophyllum Nees \& Gottsche ex Lehm., Phyllothallia E.A. Hodgs. and Hymenophyton Dumort. whilst other genera like Makinoa Miyake, Sewardiella Kashyap, Sandeothallus R.M. Schust., Greeneothallus Hässel and Xenothallus R.M. Schust. require further study. It appears therefore that symbiosis with Mucoromycotina, like those with the more recently diverged Dikarya (Ascomycota and Basidiomycota) was lost and regained several times (Fig. 1). In contrast, symbiosis with Glomeromycotina was acquired once, after the divergence of the Haplomitriopsida, followed by several losses in the Marchantiopsida, from Sphaerocarpales and six or possibly eight families of the Marchantiales, but only one subordinal loss in the Pelliidae, from the Phyllothalliineae. While the Haplomitriopsida stand out at the base of the liverwort tree as the only lineage that apparently form exclusive symbioses with Mucoromycotina fungi, several families in the Marchantiopsida, including Conocephalaceae, Corsiniaceae, Cleveaceae, Dumortieraceae, and Marchantiaceae only harbour Glomeromycotina symbionts (Fig. 1). Absences of fungal symbionts linked to habitat preference are notable in saxicolous taxa, including members of the Cyathodiaceae, submerged aquatics such as Monosolenium Griff., taxa that grow on nutrient-rich substrates, including Marchantia polymorpha subsp. polymorpha (Nees) Gottsche et al. and M. polymorpha subsp. ruderalis Bischl. \& Boissel.-Dub. and in otherwise mycorrhizallike species from very wet habitats, i.e. Conocephalum conicum (L.) Dumort. (Pressel et al. 2010, Rimington et al. 2018). Absences are also notable in ephemeral taxa, viz. Exormotheca Mitt., Oxymitra Bisch. ex Lindenb. and Riccia L. Recent genetic analyses of the model species $M$. polymorpha subsp. polymorpha have revealed that in this species genes required for successful arbuscular mycorrhizal colonization are missing (Bowman et al. 2017) while these are present in closely related mycorrhizal-like species such as M. polymorpha subsp. montivagans Bischl. \& Boissel.-Dub. (Bowman et al. 2015). Thus, the inability to form mycorrhizal-like associations, through secondary loss of symbiosis, may represent an adaptation to specific habitats, in the case of Marchantia as a weedy colonizer of highly disturbed, nutrient-rich habitats (Bowman et al. 2017).

Glomeromycotina (syn. Glomeromycota) and Mucoromycotina are sub-phyla within Mucoromycota (Spatafora et al. 2016). While uncertainties remain on the timing of the origin of Mucoromycota (Berbee et al. 2017) and the order of divergence of Mucoromycotina and Glomeromycotina, with contrasting topologies placing either subphylum as more closely related to the Dikarya (Schüßler et al. 2001, James et al. 2006, Bidartondo et al. 2011, Chang et al. 2015, Spatafora et al. 2016, Uehling et al. 2017), recent phylogenomic analyses indicate that both lineages evolved prior to or concomitant with the initial colonisation of land by plants (Schüßler \& Walker 2011, Chang et al. 2019). This evidence, together with the demonstration that the genes required for mycorrhization are conserved across all land plant lineages, including Haplomitriopsida liverworts (Wang et al. 2010, Delaux et al. 2013) strongly indicate that both symbioses are ancient and that symbiotic Mucoromycotina and Glomeromycotina likely co-evolved with liverworts since the dawn of plant terrestrialisation (Field \& Pressel, 2018, Rimington et al. 2020).

Given the likely ancient origin of Glomeromycotina symbioses it was most surprising that, until recently, molecular identifications of glomeromycete symbionts in liverworts showed these to be invariably members of the Glomeraceae, the most recently diverged family (Russell \& Bulman 2005, Ligrone et al. 2007, Bidartondo et al. 2011). This evidence, albeit based on only a handful of species, raised the possibility that the AM symbiosis in liverworts may in fact be derived via host-shifting from angiosperms (Selosse et al. 2005). However, more recent and sample-intensive molecular analyses have shown that liverworts frequently associate with ancient lineages of Glomeromycotina, more so than flowering plants, with every order detected in the Marchantiopsida and with diverse fungi often co-colonising the same host (Rimington et al. 2018), e.g. Marchantia was found to be colonised by members of the Claroideoglomeraceae, Diversisporaceae and Archaeosporaceae, alongside Glomeraceae. These findings confirm the ancient origin of the 
Glomeromycotina-liverwort symbiosis, indicate that liverworts are a global reservoir of Glomeromycotina diversity likely acting as an overlooked source of arbuscular mycorrhizal inoculum for flowering plants, and dispel the notion that liverworts exhibit specificity towards members of the Glomeraceae (Rimington et al. 2018).

The cytology of colonisation by Glomeromycotina in liverworts, as described in detail before (Ligrone et al. 2007, Pressel et al. 2010, Rimington et al. 2018) is also indicative of a single and ancient origin of the symbiosis. Glomeromycotina fungi are known to produce a range of structures inside their liverwort host cells that are strikingly similar to those formed by the same fungi in vascular plants. While considerable variation exists in the size of these structures, e.g. vesicles and in their position, with diverse patterns of colonisation observed across genera (Ligrone et al. 2007, Rimington et al. 2018) (Fig. 2A-D), arbusculated coils and/or arbuscules, which are not always produced by Glomeromycotina in flowering plants (Smith \& Smith 1997, Read et al. 2000), are a constant feature in liverworts.

In contrast to the well characterised cytology of the liverwort-AM symbiosis, a diagnostic range of structures and interfaces produced by Mucoromycotina symbionts colonising liverworts remains somewhat elusive. As described in detail before (Carafa et al. 2003, Duckett et al. 2006, Field et al. 2015a), the cytology of colonisation by Mucoromycotina symbionts in Treubia and Haplomitrium is highly distinctive, consisting of both inter and intracellular phases of colonisation characterised by ventral intracellular tightly wound coils of fine hyphae with small vesicles/lumps and pseudo-parenchyma-like hyphal structures filling the mucilage-containing dorsal intercellular spaces. The same cytology and colonisation patterns have also been described in the gametophytes and sporophytic protocorms of Lycopodium spp. (Duckett \& Ligrone 1992, Schmidt \& Oberwinkler 1993) and Lycopodiella inundata (Hoysted et al. 2019, 2020), which we now know to be also colonised by Mucoromycotina fungi (Rimington et al. 2015, Pressel et al. 2016, Hoysted et al. 2019). However, in other liverwort taxa where Mucoromycotina symbionts have been reported (Bidartondo et al. 2011, Field et al. 2016, Hoysted et al. 2019, Rimington et al. 2019, 2020), all of which lack intercellular spaces in their thalli and may form simultaneous symbioses with AMF, it has proved more difficult to identify which structures are produced by which fungal group (Field et al. 2016). The recent reclassification of fine root endophyte fungi (FRE Glomus tenue (Greenall) I.R. Hall or Planticonsortium tenue (Greenall) C. Walker \& D. Redecker; Walker et al. 2018) from the Glomeromycotina into the Mucoromycotina (Orchard et al. 2017a, Walker et al. 2018) has shed some light on what may represent Mucoromycotina-specific structures in liverworts and other plant lineages (Hoysted et al. 2019, 2020). Fine root endophytes, widespread globally and across vascular plants, have traditionally been distinguished from the 'coarse' glomeromycete endophytes on the basis of their gross morphology characterised by much finer hyphae ( $<2 \mu \mathrm{m}$ in diameter), small intercalary and terminal vesicles and fine arbuscules (Orchard et al. 2017a, b). Similar structures have been variously but not consistently observed in liverworts engaged in dual associations with both Glomeromycotina and Mucoromycotina symbionts. In Neohodgsonia mirabilis (Perss.) Perss. both 'coarse' and 'finer' arbuscules have been described (Field et al. 2016, 2019) (Fig. 2E, F), and in Fossombronia, which harbours the greatest diversity of both Glomeromycotina and Mucoromycotina symbionts (Rimington et al. 2018, 2019), fine hyphae with intercalary and terminal small vesicles (Fig. $2 \mathrm{H}$ ) are often present alongside typical Glomeromycotina arbuscules, coils and larger vesicles (Hoysted et al. 2019) (Fig. 2G). Resynthesis experiments using axenic cultures of a range of liverwort taxa other than Haplomitriopsida (Field et al. 2015a) and Mucoromycotina isolates combined with detailed cytological and ultrastructural analyses are now needed to characterise precisely Mucoromycotina specific structures and interfaces in liverworts and, potentially, across the land plant phylogeny.

The latest molecular analyses have shown that the same Mucoromycotina fungi colonising liverworts are also present in the roots of adjacent vascular plants (Hoysted et al. 2019), indicating that Mucoromycotina symbionts may be as widespread as AMF across the land plant phylogeny. In the last decade physiological studies in liverworts have not only demonstrated unambiguously that both Glomeromycotina (Humphreys et al. 2010, Field et al. 2012) and Mucoromycotina associations represent nutritional mutualisms (Field et al. 2015a, 2016) but have also identified important differences in the nutritional benefits afforded to liverwort hosts by the two fungal groups. It appears that Mucoromycotina symbionts have a more prominent role in nitrogen nutrition, being able to access and transfer $\mathrm{N}$ from both inorganic (Field et al. 2016) and organic sources (Field et al. 2019). A major research question now is whether the different functional significance of the two symbioses observed in liverworts, also extends to the rest of the land plants, with recent experiments in the lycophyte Lycopodiella inundata indicating that this may well be the case (Hoysted et al. 2019, 2020).

\section{Ascomycota and Basidiomycota associations in the Jungermanniopsida}

While research on the diversity and distribution of fungal symbioses in Marchantiopsida and Pelliideae has increased exponentially in the last decade, largely spurred on by the discovery of Mucoromycotina symbionts alongside AMF in both groups, parallel studies on basidiomycetous and ascomycetous associations in the Jungermanniopsida have lagged 

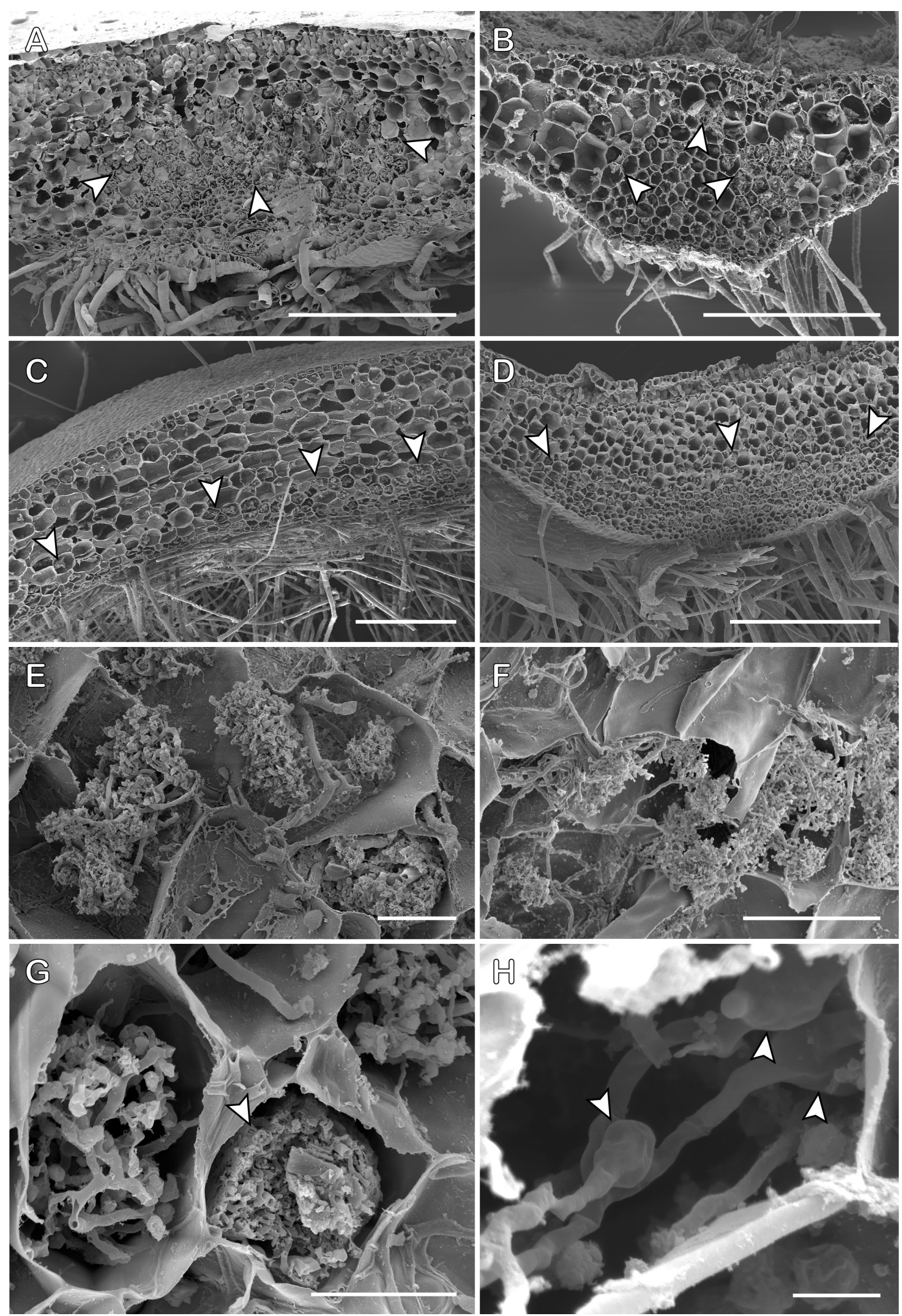

FIGURE 2. Fungal colonisation in thalloid liverworts. Scanning electron micrographs. A. Extensive fungal colonisation in the thallus central midrib in Marchantia pappeana Lehm. (arrowed), in the region overarching the midrib in Dumortiera hirsuta (Sw.) Nees (B, arrowed), and in the ventral cell layers in Monoclea forsteri Hook. (C, arrowed), and Lunularia cruciata (L.) Dumort. ex Lindb. (D, arrowed). E, F. Fungal structures in Neohodgsonia mirabilis (Perss.) Perss. include both 'coarse' (E) and much finer arbscules (F). G, H. Fungal colonisation in Fossombronia foveolata Lindb. G. Arbuscule and tighly wound coil of fine hyphae (arrowed). H. Fine hyphae with small swellings (arrowed). Scale bars: (A-D) 500 $\mu$ m; (F) $50 \mu \mathrm{m}$; (E, G) $20 \mu \mathrm{m}$; (H) $5 \mu \mathrm{m}$. 
behind. Indeed, our current understanding of the diversity and distribution of these associations in liverworts has not changed significantly since we last reviewed the topic in Pressel et al. (2010) (Fig. 1). It is well established that the Aneuraceae, which with the Metzgeriaceae and Pleuroziaceae form the most derived clade within the thalloid liverworts (Davis 2004, Forrest \& Crandall-Stotler 2004, Forrest et al. 2006, He-Nygren et al. 2006) are the only simple thalloids to harbour basidiomycetes, mainly members of the genus Tulasnella J. Schröt. (Bidartondo et al. 2003, Kottke et al. 2003, Kottke \& Nebel 2005, Bidartondo \& Duckett 2010, Preußing et al. 2010, Krause et al. 2011), with only sporadic reports of Serendipita P. Roberts (Sebacina Tul. \& C. Tul.) symbionts in this family (Duckett \& Ligrone 2008, Bidartondo \& Duckett 2010, Preußing et al. 2010). In contrast, sebacinoid symbionts are widespread in leafy liverworts, having been reported in members of diverse families including Barbilophozia Loeske, Diplophyllum (Dumort.) Dumort., Lophozia (Dumort.) Dumort., Scapania (Dumort.) Dumort. and Tritomaria Schiffn. ex Loeske in the Scapaniaceae, Nardia Gray in the Jungermanniaceae, Saccogyna Dumort. in the Geocalycaceae and Southbya Spruce, and possibly Gongylanthus Nees, in the Arnelliaceae (Read et al. 2000, Kottke et al. 2003, Kottke \& Nebel 2005, Nebel et al. 2004, Duckett et al. 2006b, Bidartondo \& Duckett 2010, Newsham \& Bridge 2010). However, the most widespread symbiosis by far in leafy liverworts (Kowal et al. 2018, Rimington et al. 2020) involves ascomycetes symbionts, first acquired in the rhizoids of the Schistochilaceae (Pressel et al. 2008a, b) with several families in Jungermanniideae, including Schistochilaceae, Lepidoziaceae, Calypogeiaceae, Cephaloziaceae and Cephaloziellaceae shown to be consistently colonized by Rhizoscyphus (Pezoloma, Hymenoscyphus or Pezizella) ericae (D.J. Read) W.Y. Zhuang \& Korf (Upson et al. 2007), the same fungus known to form ericoid mycorrhizas with the roots of ericaceous plants (Read et al. 2004, Smith \& Read 2008). Because the symbiotic status of many Jungermanniideae families remains to be investigated, it is not yet possible to obtain a comprehensive picture of the distribution of Basidiomycota and Ascomycota associations in this subclass and thus determine whether these symbioses had a single or multiple origins (Pressel et al. 2010, Rimington et al. 2020). Current understanding of the diversity and distribution of Basidiomycota in liverwort phylogenies, and demonstrations that basidiomycete symbionts are highly host specific, indicate that Basidiomycota associations likely had multiple origins (Duckett et al. 2006b, Bidartondo \& Duckett 2010). On the other hand, DNA sequencing data identifying but one fungus, Rhizoscyphus ericae (Upson et al. 2007), in the rhizoids of all ascomycete-containing lineages, together with cross-inoculation experiments (Duckett \& Read 1995, Chambers et al. 1999, Read et al. 2000, Upson et al. 2007) point to a possible monophyletic origin of the liverwort-Ascomycota symbiosis. However, cytological differences between the rhizoidal colonisation of different liverwort groups (Pressel et al. 2010) suggest that multiple origins are equally likely. A decade ago we proposed that identifying the fungus colonising the swollen rhizoid apices of Mylia anomala, which stand out by being considerably larger than those in the ascomycete-containing genera but resemble those of the related southern hemisphere Balantiopsidaceae (de Roo et al. 2007, Duckett \& Ligrone, 2008a), should be a priority for investigation (Pressel et al. 2010). Here we report for the first time the results of a molecular and cytological study aimed at resolving the identity of the rhizoidal fungus in $M$. anomala and test the hypothesis that Mylia also harbours Rhizoscyphus ericae via its likely schistochilaceous ancestry (de Roo et al. 2007, Pressel et al. 2010).

\section{The 'odd' case of Mylia anomala swollen rhizoids}

From the distribution of fungi overall in the Jungermanniales, the swollen rhizoids of Mylia anomala immediately stand out as highly enigmatic; without cytological and molecular data it is very difficult to even guess at the nature of their mycobiont. Growing over Sphagnum L., together with a mixture of ascomycete and basidiomycete-associated liverworts, members of both of these fungal groups should be readily available as possible colonists of its rhizoids.

Mylia anomala is the only Mylia species with swollen rhizoids; the other three species (Paton, 1999) all appear to lack fungi (pers. obs., Duckett et al. 1991). Traditionally located in the Jungermanniaceae (e.g., Paton 1999), Grolle (1963) placed Mylia in an independent family, Myliaceae, whereas Schuster (1969) erected the subfamily Mylioideae only for the familial level to be reinstated by Engel \& Braggins (2005). The last two authors, on the basis of cell wall characters, but ignoring the unique rhizoids, suggested that $M$. anomala was best retained in the Jungermanniaceae but as a new genus, Leiomylia, that they placed in its own subfamily within Jungermanniaceae, the Leiomylioideae. In earlier molecular analyses, but based only on M. taylorii (Hook.) Gray, Mylia is an isolated lineage (Hentschel et al. 2006, 2007). However, de Roo et al. (2007) demonstrated that Leiomylia J.J. Engel \& Braggins/Mylia anomala and M. taylorii have a well-supported sister relationship, thus calling into doubt the generic status of Leiomylia. The two species form a long branch in both Bayesian and parsimony phylogenetic analyses. They are resolved as either sister to the majority of Jungermanniales (parsimony) including all the taxa with either ascomycete or basidiomycete symbionts or, more likely, within the Jungermanniineae (Bayesian analysis) as sister to a clade that is mostly fungus-free, except for basidiomycetes in a few scattered genera (Gongylanthus, Southbya, Nardia) and a few ascomycetes in others 
(Anastrophyllum, Calypogeia Raddi, Eremonotus, Geocalyx, Roivainenia Perss.) (Bidartondo \& Duckett 2010). With Pachyschistochila (R.M. Schust.) R.M. Schust. \& J.J. Engel as the immediate sister to Mylia in both topologies the most likely hypothesis for the origin of its symbiosis is that it retained Rhizoscyphus from a schistochilaceous ancestor. This appears all the more likely since cross-colonisation experiments revealed that the Pachyschistochila fungus forms typical rhizoidal associations across a range of liverworts (Pressel et al. 2008b). More recent phylogenetic analyses have confirmed L. anomala and $M$. taylorii as sister taxa in a strongly supported clade and the return of Leiomylia to the Myliaceae together with the removal of Myliaceae from the Jungermanniineae, and validation of a newly established monogeneric suborder Myliineae to house it (Shaw et al. 2015).

In order to determine the identity of the fungus colonising the rhizoids of Mylia anomala and to compare the cytology of the association with that of other liverworts we prepared samples of M. anomala, collected from three widely separate sites in Southern England, Scotland and Ireland for scanning and transmission electron microscopy. Further, we sequenced the fungal nuclear ribosomal internal transcribed spacer region, aligned the DNA sequences obtained together with the most similar sequences retrieved from GenBank via BLAST, and then we used the alignment to generate a distance tree using neighbour-joining as described previously (Bidartondo \& Duckett 2010). Representative newly obtained DNA sequences are accessioned in GenBank (MZ062410-MZ062415).

It is immediately apparent from scanning electron micrographs (Figs. 3,4) that the swollen-tipped rhizoids in Mylia are much larger than those that harbour Rhizoscyphus. Those in the other families have rhizoid shafts $10 \mu \mathrm{m}$ or less in diameter with swollen tips between 25 and $35 \mu \mathrm{m}$ (Fig. 3A) compared to the 20-30 $\mu \mathrm{m}$ shafts and 50-80 $\mu \mathrm{m}$ terminal swellings in Mylia (Fig. 3B, C). The swollen-tipped rhizoids in Cephalozia (Dumort.) Dumort. are thin-walled (Fig. 4C) whereas those in Mylia are thick with hyphae often running along their multiple stratifications (Fig. 3D, Fig. 4A). Numerous Golgi bodies in the host cytoplasm presumably contribute to the prominent interfacial matrix (Fig. 3D-G) around the hyphae where amyloid deposits are frequent (Fig. 3G). Simple septa and Woronin bodies confirm the ascomycetous nature of the symbiont (Fig. 4G). Two other striking features of the host rhizoids are the compound oil bodies typical of Mylia anomala (Fig. 3E), compared with the simple oil droplets in Cephalozia (Paton,1999) and starch grains in the plastids (Fig. 3E-G). The latter are notably rare in the infected cells in other liverworts (Fig. 4D) and hornworts.

Molecular analyses show that the fungi colonising Mylia rhizoids comprise several species of Meliniomyces Hambl. \& Sigler (Hambleton \& Sigler 2005) alongside Cadophora finlandica (C.J.K. Wang \& H.E. Wilcox) T.C. Harr. \& McNew and Rhizoscyphus ericae (Fig. 5), all currently placed in the Hymenoscyphus ericae (D.J. Read) Korf \& Kernan aggregate. Fungi in the genus Meliniomyces, including M. variabilis Hambl. \& Sigler and M. bicolor Hambl. \& Sigler are known to form ericoid mycorrhizas with several species in the Ericaceae (Grelet et al. 2009) and some, e.g. M. bicolor, can be ectomycorrhizal with temperate forest trees (Villarreal-Ruiz et al. 2004). Meliniomyces and Cadophora finlandica have often also been reported to grow as endophytes in the roots of non-host plants (Tedersoo et al. 2009, Perotto et al. 2018).

The present demonstration that the association in Mylia anomala is different from others previously described in liverworts, all of which include only Rhizoscyphus ericae, points to possible independent evolution and underlines the current subordinal status of the Myliineae. We have failed to find fungi in a range of genera in the allied families Trichotemnomataceae (Trichotemnoma R.M. Schust.), Balantiopsidaceae (Balantiopsis Mitt., Isotachis Mitt.), Acrobolbaceae (Acrobolbus Nees, Goebelobryum Grolle, Lethocolea Mitt., Marsupidium Mitt., Tylimanthus Mitt.), Blepharidophyllaceae (Blepharidophyllum Ångstr., Clandarium (Grolle) R.M. Schust.) whilst the next nearest family the Arnelliaceae harbours basidiomycetes. Having also drawn a blank from cytological observations on other leafy families whose fungus status was previously unknown, it is now reasonable to conclude that Mylia anomala plugged the biggest gap in knowledge.

It would now be interesting to determine if the Mylia association with members other than Rhizhoscyphus ericae of the Hymenoscyphus ericae aggregate are also mycorrhizal-like in terms of function. Recently it has been shown that $R$. ericae forms nutritional mutualisms with leafy liverworts. Isotope tracer experiments have demonstrated that R. ericae colonising the rhizoids of Cephalozia bicuspidata (L.) Dumort. transfers nitrogen and phosphorus to its host in exchange for photosynthesis-fixed carbon (Kowal et al. 2018). Whether associations with other ascomycete fungi, such as those inhabiting Mylia rhizoids, are also mycorrhizal-like now need experimental investigation. Another major functional knowledge gap as far as liverworts are concerned, are the basidiomycete symbioses in leafy Scapaniaceae and Arnelliaceae (Bidartondo \& Duckett 2010, Kowal et al. 2018) and thalloid Aneuraceae except in the achlorophyllous epi-parasite Aneura (Cryptothallus) mirabilis (Malmb.) Wickett \& Goffinet which obtains its carbon via an interlinked Tulasnella fungus that simultaneously forms ectomycorrhizas with trees (Bidartondo et al. 2003). 

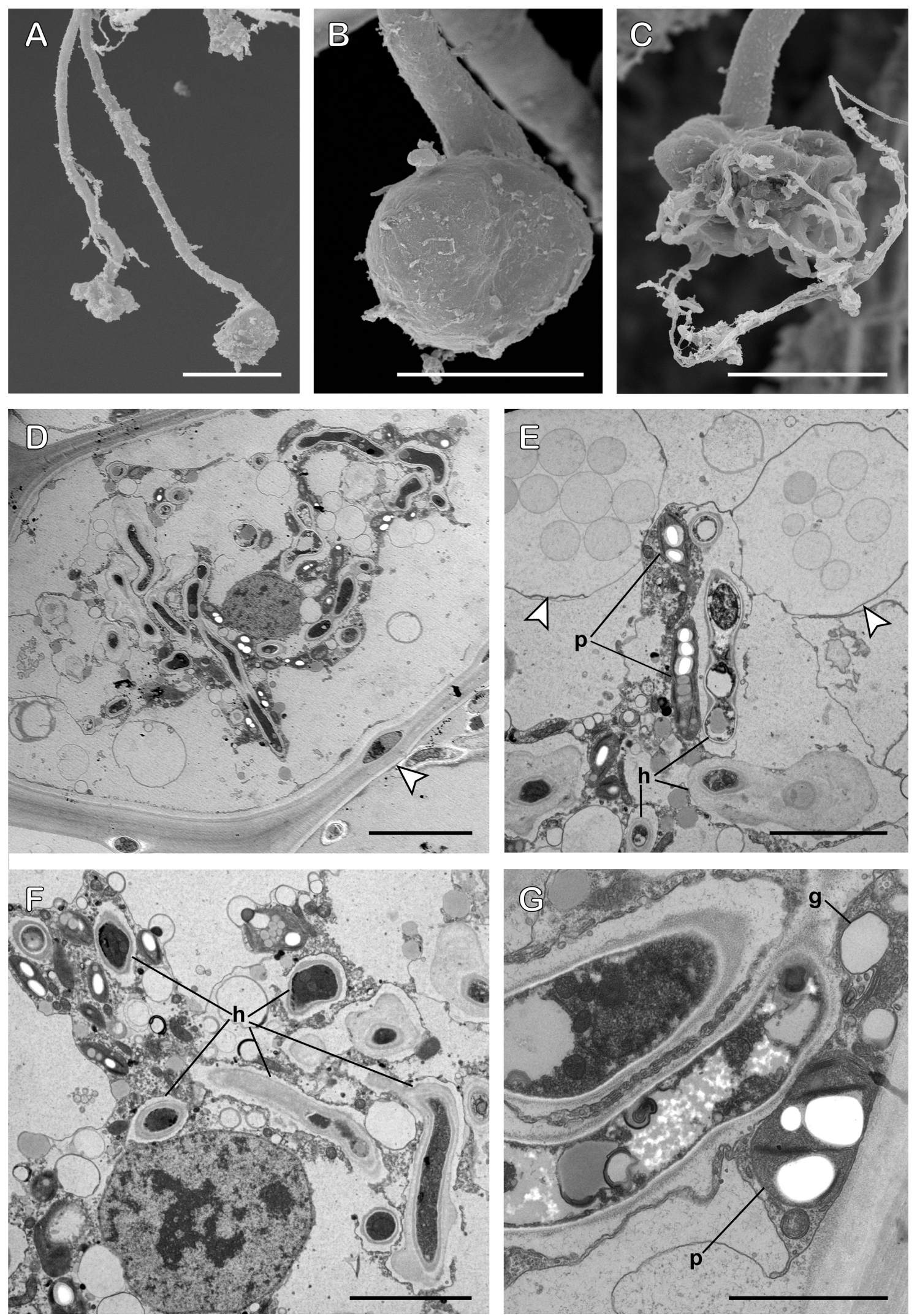

FIGURE 3. The distinct fungal assocation in Mylia anomala (Hook.) Gray vs. that in Cephalozia lunulifolia (Dumort.) Dumort.. A-C. Scanning electron micrographs. D-G. Transmission electron micrographs. A. Swollen rhizoid tip in Cephalozia lunulifolia. B-G. Mylia anomala. B, D. Large, swollen rhizoid tips. E. Thick-walled, swollen rhizoid tip packed with hyphae and showing hyphae in the wall multiple stratifciations (arrowed). E. Plastids (p) with prominent starch grains adjacent to fungal hyphae (h) and compound oil bodies (arrowed). F. Dense host cytoplasm surrounding fungal hyphae with prominent interfacial matrix (h). G. Golgi body (g) and plastid (p) adjacent to an hypha with amyloid deposits. Scale bars = (A-C) $50 \mu \mathrm{m}$; (D) $10 \mu \mathrm{m}$; (C, F) $5 \mu \mathrm{m}$; (G) $1 \mu \mathrm{m}$. 


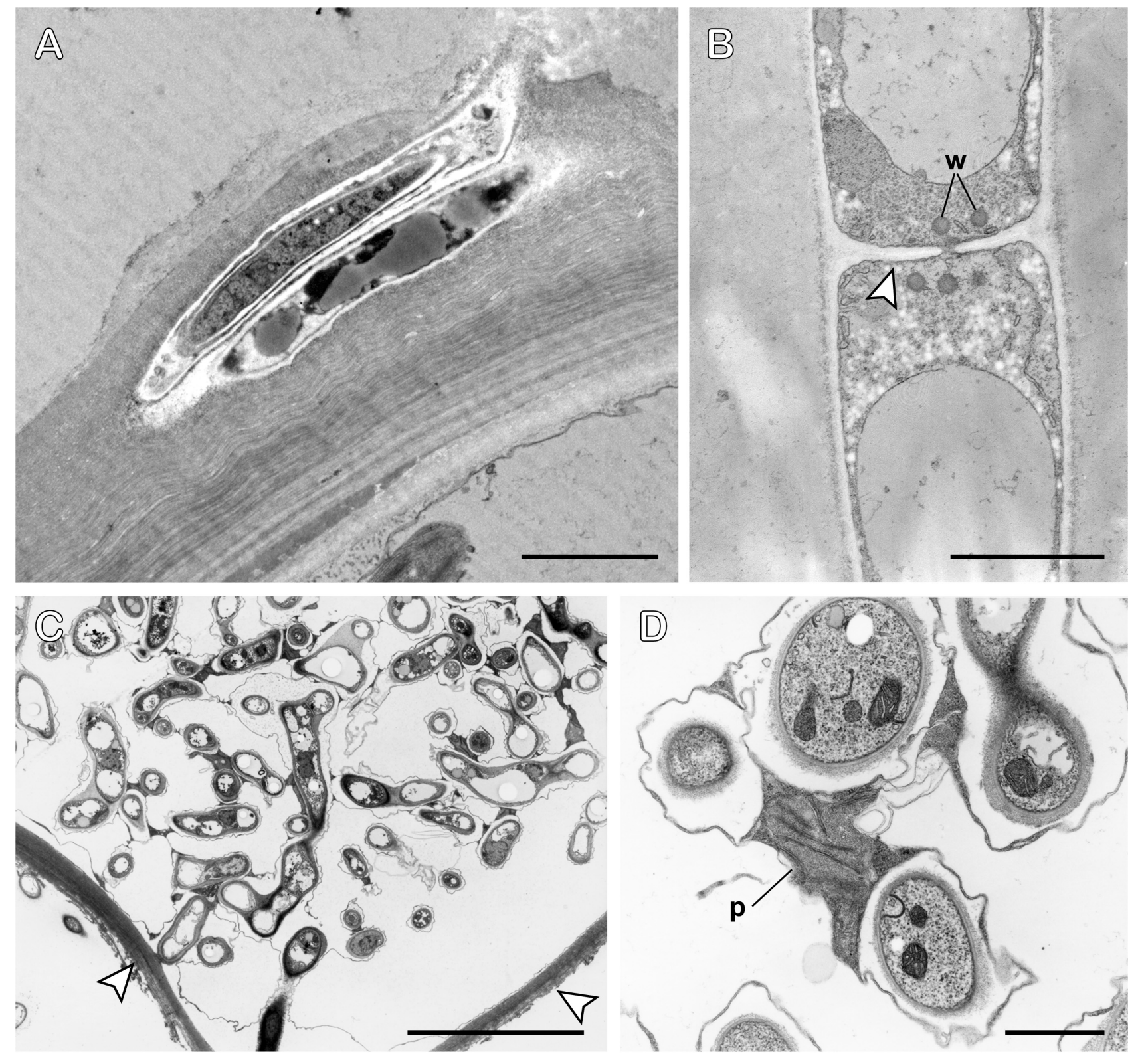

FiGURE 4. The distinct fungal association in Mylia anomala vs. that in Cephalozia connivens (Dicks.) Lindb. Transmission electron micrographs. A, B. Mylia anomala. A. Detail of fungal hyphae in the multistratose wall of a swollen rhizoid tip. B. Simple septum (arrowed) with Woronin bodies (w). C, D. Cephalozia connivens C. Thin-walled (arrowed) rhizoid tip packed with fungus. D. Starch-free plastid (p) adjacent to fungal hyphae. Scale bars = (C) $10 \mu \mathrm{m}$; (A) $2 \mu \mathrm{m} ;(\mathrm{B}, \mathrm{D}) 1 \mu \mathrm{m}$.

\section{Fungal associations in hornworts}

Until recently, investigations of fungal associations in hornworts have been limited to two investigations. The study by Ligrone (1988) showed that the ultrastructure of the fungus colonizing the thallus of Phaeoceros laevis (L.) Prosk. was very similar to that of AM fungi in vascular plants and thalloid liverworts. A decade later, the demonstration by Schüßler (2000) that Anthoceros punctatus L. was able to form an arbuscular mycorrhizal-like symbiosis with two isolates of Glomus claroideum Schenck \& Smith, corroborated the notion that hornworts are symbiotic with members of the Glomeromycotina. The subsequent molecular detection of Endogone-like Mucoromycotina fungi in two species of Phaeomegaceros R.J. Duff, J.C. Villarreal, Cargill \& Renzaglia alongside that of Glomeromycotina in Phaeoceros carolinianus (Michx.) Prosk., P. laevis (L.) Prosk., Anthoceros laminifer Steph. and A. husnotii Steph. (Bidartondo et al. 2011) indicated that hornworts, on a par with thalloid liverworts, might be able to engage with a wider repertoire of symbiotic fungi than previously thought, as subsequently confirmed by the first global molecular and cytological study of fungal associations in this group (Desirò et al. 2013). Desirò et al. (2013) showed that both Glomeromycotina and Mucoromycotina symbioses are widespread across hornworts, with nine of the eleven recognized hornwort genera 
(Villarreal \& Renner 2012) found to harbour diverse glomeromycete and mucoromycete symbionts, often together in the same plant host. Fungal associations are notably absent in Leiosporoceros dussii (Steph.) Hässel, the only species in Leiosporoceros Hässel sister genus to all other hornworts, with secondary losses of symbioses associated, as in liverworts (Pressel et al. 2010), with change of habitat from terrestrial to epiphytic, in Dendroceros Nees, or in species within symbiotic genera growing in permanently wet habitats such as Megaceros flagellaris (Mitt.) Steph. and the New Zealand endemic Nothoceros giganteus (Lehm. \& Lindenb.) J. Haseg. ex J.C. Villarreal, Hässel \& N. Salazar. The symbiotic status of Phymatoceros Stotler, W.T. Doyle \& Crand.-Stotl., reported to harbour fungal endophytes (Stahl 1949) remains to be confirmed by cytological and molecular analyses.

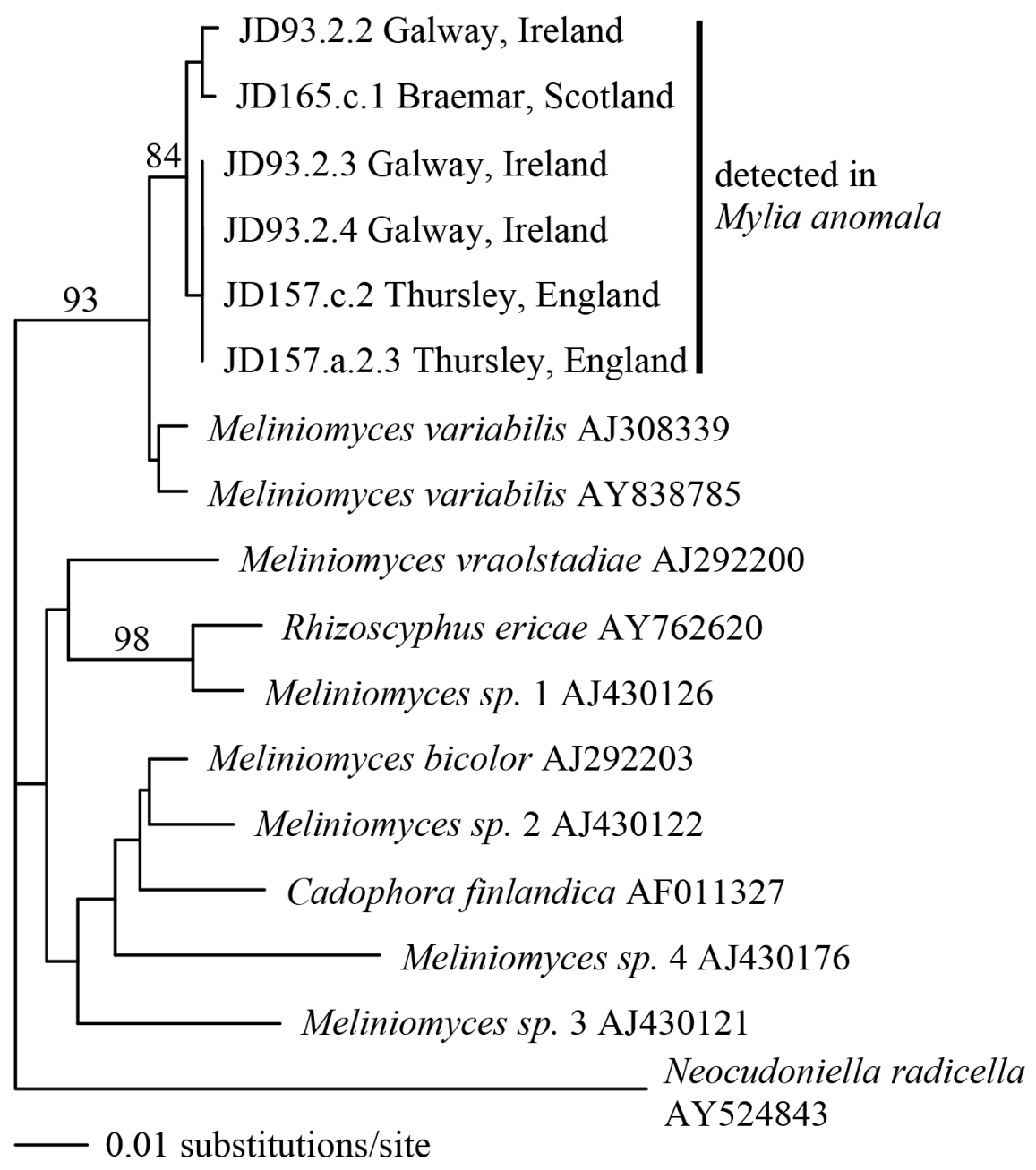

FIGURE 5. Phylogenetic placement of fungal associates of Mylia anomala within the "Hymenoscyphus ericae aggregate" (sensu Hambleton \& Sigler 2005). This fungal nuclear internal transcribed spacer phylogram is based on neighbour joining with bootstrap (values $>70 \%$ are shown) of ten representative fungal isolate DNA sequences retrieved from GenBank and six sequences from thalli representing three sites. Neocudoniella radicella L.M. Kohn, Summerb. \& Malloch was used as the outgroup.

Similarly to thalloid liverworts, hornworts form symbioses with nearly all clades of Glomeromycotina (Desirò et al. 2013), and are more often colonized by early divergent lineages than flowering plants (Rimington et al. 2018). While this finding indicates that both symbioses are likely ancient, the taxonomic distribution of Glomeromycotina and Mucoromycotina fungi in hornworts does not allow to infer conclusively the symbiotic history of these fungi and whether either lineage or both were present in the ancestor of hornworts (Desirò et al. 2013, Rimington et al. 2018). The absence of symbiosis in the earliest Leiosporoceros and the presence of both fungi in the Anthocerotaceae (Fig. 1), which include Anthoceros and Folioceros, and is the sister group to the remaining taxa (Söderström et al. 2016), point to three possible scenarios: Glomeromycotina as ancestral and followed by at least five losses of AM fungi together with three gains of Mucoromycotina; ancestral Mucoromycotina with five subsequent losses of symbiosis (Desirò et al. 2013); or both fungal lineages having formed the ancestral hornwort-fungus symbiosis (Rimington et al. 2018). 

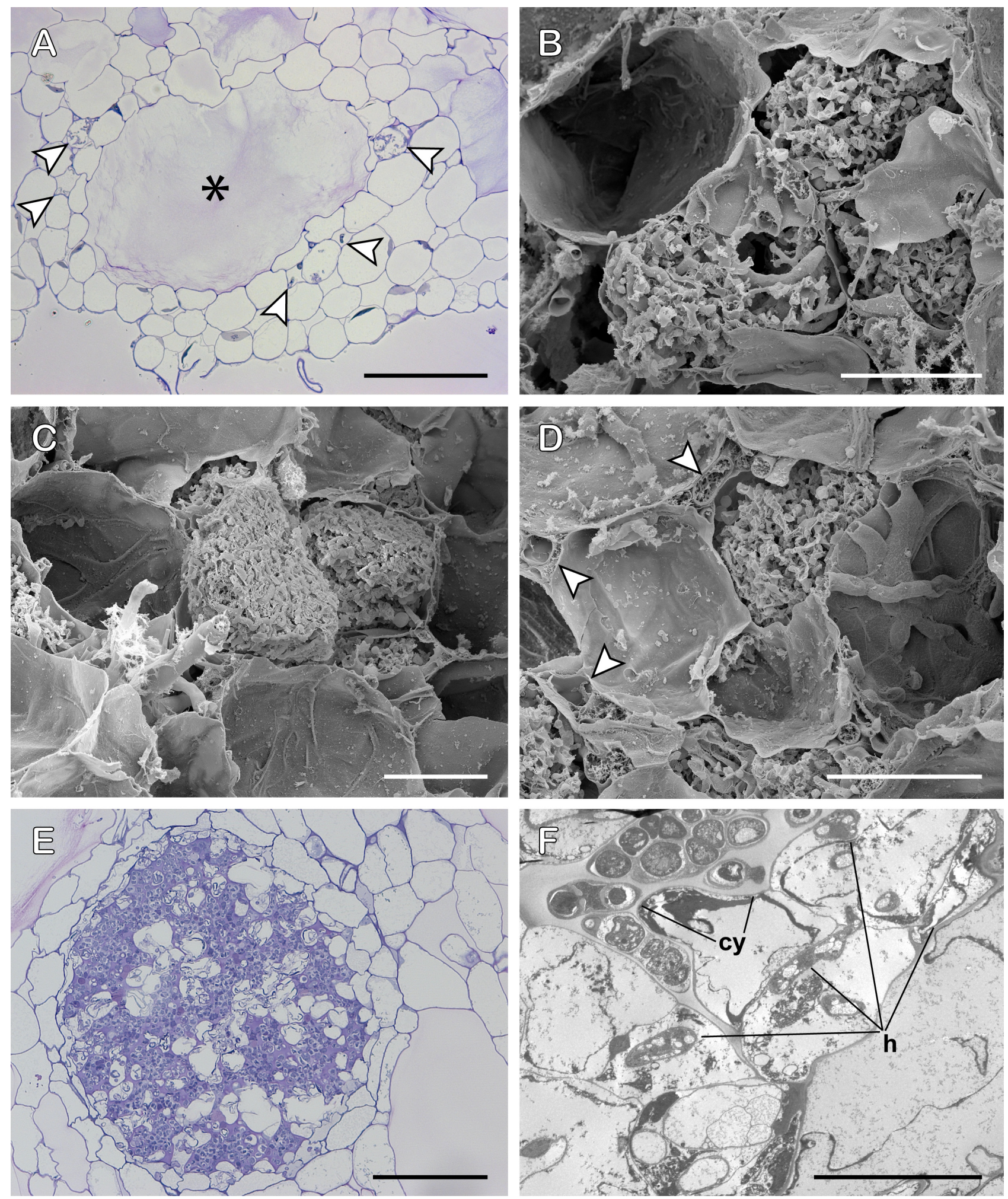

FIGURE 6. Fungal colonisation in hornworts. A, E. Light micrographs. B-D. Scanning electron micrographs. F. Transmission electron micrographs. A. Intracellular and intercellular fungal hyphae scattered in the thallus of Anthoceros cristatus Steph., the large mucilage cavities (*) are fungus-free. B-D. Fungal structures in the thallus of Phaeoceros himalayensis (Kashyap) Prosk. ex Bapna \& G.G. Vyas include intracellular arbuscules (B), tightly wound coils (C) and intercellular hyphae (D, arrowed). E, F. Anthoceros punctatus L. cyanobacterial colonies (cy) with closely associated hyphae (h). Scale bars = (A, E) $100 \mu \mathrm{m} ;(\mathrm{B}-\mathrm{D}, \mathrm{F}) 20 \mu \mathrm{m}$. 
Compounding these uncertainties is the currently unresolved position of hornworts in land plant phylogeny. Several recent phylogenomic studies have challenged the general consensus of liverworts as sister to all other embryophytes and hornworts sister to the vascular plants (Qiu et al. 2006) and found strong support for the monophyly of liverworts and mosses (Setaphyta) (e.g. Wickett et al. 2014, Puttick et al. 2018, Sousa et al. 2018, 2020). However, whether hornworts are the sister group to the Setaphyta in monophyletic bryophytes (Harris et al. 2020) or, in paraphyletic bryophytes, either the earliest divergent embryophyte lineage or the one most closely related to vascular plants (Puttick et al. 2018, Sousa et al. 2020) remains to be established.

The cytology and distribution of fungal colonization in hornworts (Desirò et al. 2013) show both parallels and differences with those in thalloid liverworts (Fig. 6). Fungal structures attributable to both Glomeromycotina, i.e. arbuscules with trunk hyphae and large vesicles, and Mucoromycotina symbionts (Fig. 6A-D), e.g. intercellular semiparenchymatous hyphal structures and thick, multilayered hyphae in the mucilage-filled intercellular spaces, as typical of Mucoromycotina associations in Treubia and Haplomitrium (Carafa et al. 2003, Duckett et al. 2006, Field et al. 2015a), have been described in the thalli of diverse hornwort species (Desirò et al. 2013). However, while in liverworts fungi usually occupy specific regions of the thalli (Fig. 2A-D) (Ligrone et al. 2007, Pressel et al. 2010, Field et al. 2016, Rimington et al. 2018) or in the case of Haplomitrium are restricted to the epidermal layers of its rhizoidless underground axes (Carafa et al. 2003, Field et al. 2015a), such distinct zonation is not present in hornworts, where fungi are more randomly distributed in the thallus except for the large mucilage cavities, when these are present (Fig. 6A). In contrast to the ubiquitous role of rhizoids as conduits for fungal entry in thalloid liverworts (Ligrone et al. 2007, Pressel et al. 2010), hornwort rhizoids are invariably devoid of fungi (Ligrone 1988, Desirò et al. 2013, pers. observations), a situation with a single liverwort counterpart in Treubia. In Treubia fungal entry is via mucilage-filled spaces between the epidermal cells (Duckett et al. 2006a, Pressel et al. 2010); whether in hornworts fungal entry is via mucilage clefts (Ligrone 1988) remains to be confirmed.

The functional significance of fungal associations in hornworts also remains to be established. In contrast to liverworts, where different taxa are either obligate symbiotic or lack fungi altogether, the occurrence of fungal associations in hornworts appears variable, with the same species variously found to harbour either or both Glomeromycotina and Mucoromycotina symbionts or to be fungus-free (Desirò et al. 2013). In liverworts, the ability to form associations with both fungal groups is thought to confer nutritional advantages to the host plant. Dual symbioses in Neohodgsonia mirabilis and Allisonia cockaynei (Steph.) R.M. Schust. have been shown to afford greater gains of phosphorus and nitrogen to their liverwort hosts than symbioses involving a single fungal group, i.e. Mucoromycotina in Treubia lacunosa (Colenso) Prosk. and Haplomitrium gibbsiae (Steph.) R.M. Schust. (Field et al. 2015a) and Glomeromycotina in Marchantia (Preissia) quadrata Scop. and Marchantia paleacea Bertol. (Field et al. 2012), but at a greater carbon cost (Field et al. 2016). Recent physiological analyses using microcosm and isotope tracer experiments have indicated that Mucoromycotina symbionts are functionally distinct yet complementary to Glomeromycotina, because of their greater ability to access and transfer nitrogen to their liverwort hosts from both inorganic and organic sources (Field et al. 2019). Together these findings suggest that the ability to engage with both Mucoromycotina and Glomeromycotina fungal partners may offer additional plasticity in terms of nutrient uptake to liverworts (Field et al. 2016) by increasing the availability and range of nutrient pools. The apparent greater ability of Mucoromycotina over Glomeromycotina symbionts to supply liverwort hosts with organically derived nitrogen is likely to provide a competitive advantage in disturbed, primary successional habitats where nitrogen may be limiting and the distribution of organic nutrients patchy (Field et al. 2019).

An added 'symbiotic' dimension in hornworts is the ubiquitous presence of $\mathrm{N}_{2}$-fixing cyanobacteria endophytes in this group (Renzaglia et al. 2009, Frangedakis et al. 2021), mostly in the genus Nostoc Vaucher ex Bornet \& Flahault, which have been shown to transfer up to $80 \%$ of their fixed nitrogen to their hornwort hosts (Adams 2002, Adams \& Duggan 2008) (Fig. 6E). Cyanobacteria endophytes in liverworts are restricted to Blasia L. and Cavicularia Steph. in the Blasiales (Adams 2002, Rikkinen \& Virtanen 2008), the only early divergent liverwort lineage which consistently lack fungal symbionts (Pressel et al. 2010), and are absent from the pteridophytes except for the aquatic fern Azolla Lam., which also lack fungi (Whitton 1993). Some moss species associate with cyanobacteria but here the association is strictly epiphytic (Warshan et al. 2017) or within the dead hyalocysts in Sphagnum (Meeks 1989) and endosymbioses with fungi have never been reported in this group (Pressel et al. 2010, Field et al. 2015b). As such, hornworts stand out as the only spore-producing extant embryophyte lineage to associate with both fungal and cyanobacterial symbionts. Seed plant counterparts are found in the cycads (Lindblad \& Bergman 2018) and possibly Gunnera L. (Bergman et al. 1992). It has been suggested that in cycads AM fungi may provide phosphorus in phosphorus-limited environments to the cyanobacteria (Fisher \& Vovides 2004), a well-known phenomenon in the more recently evolved tripartite symbioses between legumes, rhizobia and arbuscular mycorrhizal fungi (Azcón et al. 1991, Xavier \& Germida 2002, 
2003, Jia et al. 2004). Mycorrhizas in Gunnera have only been reported once, in the endemic Hawaiian Gunnera petaloidea ssp. kauaiensis (A. Gray) Doyle (Koske et al. 1992), but here fungus and cyanobacterium are spatially separated, the latter being restricted to specialised stem glands.

Observations that in hornworts fungal hyphae often occur in close associations with cyanobacterial colonies (Fig. 6E, F) may be indicative of a functional relationship between microbes (Desirò et al. 2013). It has been argued that the more abundant the cyanobacteria the less likely are hornworts to harbour fungi, since fungi are lacking from Leiosporoceros, which has the most extensive cyanobacterial colonies (Villarreal \& Renzaglia 2016) and in the only cyanobacteria-containing liverworts, the fungus-free Blasiales, Nostoc are more numerous than in hornworts (Desirò et al. 2013). However, it should be noted that cyanobacterial colonisation in Leiosporoceros is distinct from that in all other hornworts, where continuous formation of mucilage clefts supports multiple invasions of a single thallus (Villarreal \& Renzaglia 2016) and, presumably, fungal entry (Desirò et al. 2013, Ligrone 1988). In Leiosporoceros bifurcating and interconnected strands of Nostoc are locked inside the thallus following a single colonisation event in the sporeling stage through mucilage clefts whose production ceases once cyanobacterial colonies are established (Villarreal \& Renzaglia 2016). In the Blasiales, the whole symbiotic consortium (bryophyte and cyanobiont) presumably can disperse together via their Nostoc-containing stellate gemmae, possibly allowing for specific symbiotic consortia to be maintained (Costa et al. 2001). Probably the most striking cytological difference between the Nostoc colonies in Blasia and hornworts is that, in the former the surrounding cells and the filaments traversing the colonies have prominent wall ingrowths diagnostic of transfer cells (Duckett et al. 1977) whereas the corresponding cells in hornworts are thinwalled and highly vacuolate (Figure 6E, F). These features suggest very different functional relationships. Interesting to note here is that in Blasia and Cavicularia the slime papillae of the cavities housing Nostoc play a crucial role in the plant-cyanobacterium symbiosis by attracting the cyanobiont and by developing into the transfer cells mentioned before (Rikkinen 2017 and literature therein), whilst slime papillae are absent in hornworts. Whether slime papillae in other liverworts also play a role in their interactions with soil microbes (Rikkinen 2017) is currently unknown but certainly deserves further scrutiny.

Clearly, there is an urgent need to determine whether fungal associations in hornworts, like those in thalloid liverworts, are mycorrhizal-like and to investigate possible functional relationships between co-occurring fungal and cyanobacterial symbionts. Latest genomic analyses of the emerging model species Anthoceros agrestis Paton (Szövényi et al. 2015, Szövényi 2016, Frangedakis et al. 2020) have identified orthologues of all the key angiosperm genes required for the establishment and maintenance of the AMF symbiosis ( $\mathrm{Li}$ et al. 2020). Given that other bryophyte model species with published genomes, the moss Physcomitrium (Physcomitrella) patens and the liverwort Marchantia polymorpha subsp. polymorpha, both lack fungal symbionts, physiological and molecular analyses of fungal associations in Anthoceros may hold the key to unravel the origin and evolutionary history of mycorrhizal associations in land plants.

Further, the presence of cyanobacteria in the prostrate mycorrhizal axes of the 400 million years old fossil plant Aglaophyton major (Krings et al. 2009) together with genomic evidence placing the evolution of endosymbiotic Nostoc clades at ca. 950 million years ago (Warshan et al. 2018), all indicate that the land plant-cyanobacterial symbiosis may be as ancient as that formed with fungi. It is possible therefore that associations involving both fungi and cyanobacteria, as seen today in hornworts, were common at the dawn of plant terrestrialisation. An alternative hypothesis is that earliest symbioses on land involved fungi and cyanobacteria and that, through these, fungi might have become pre-adapted for mycorrhization (Schüßler 2012). Today Geosiphon pyriforme (Kütz.) v. Wettstein is the only known example of a glomeromycete fungus in endobiotic association with a cyanobacterium (Schüßler 2002, Fisher \& Vovides 2004) and, interestingly, its hyphal networks are often found associated with the rhizoids of Anthoceros and other bryophytes (Chapman \& Margulis 1988).

Whether this association represents a modern oddity or a relic of an ancient association between fungi and cyanobacteria that preceded plant terrestrialisation and the evolution of plant-fungal symbiosis remains to be established. Fungi and cyanobacteria are thought to have inhabited the terrestrial environment as part of microbial mats long before the establishment of the land flora (Edwards et al. 2015, Lenton \& Daines 2017) and Glomeromycotina have been shown to possess two additional prokaryotic (class I) ribonuclease III protein-coding genes arising by putative horizontal gene transfer from cyanobacteria, suggestive of an ancient symbiotic history between Glomeromycotina and cyanobacteria (Lee et al. 2018). 


\section{Conspectus}

The last decade witnessed major advances in understanding of bryophyte fungal associations. Extensive DNA sequencing studies have revealed that these are formed with a wider repertoire of fungal symbionts than ever envisaged at the start of the 21st Century, including newly discovered partnerships in Haplomitriopsida, Marchantiopsida and Pelliidae and throughout hornworts with members of the ancient fungal sub-phylum Mucoromycotina (Bidartondo et al. 2011, Desirò et al 2013, Rimington et al. 2018, 2019, 2020). Parallel physiological studies of liverwort-fungus associations have not only confirmed that these are mycorrhizal-like but have also highlighted key differences between Glomeromycotina and Mucoromycotina symbionts both in their sensitivity to changes in atmospheric $\mathrm{CO}_{2}$ concentrations and functionality, with Mucoromycotina having a more prominent role in liverwort nitrogen nutrition in line with their apparent ability to assimilate and transfer $\mathrm{N}$ from both inorganic and organic sources (Field et al. 2015a, 2016, 2019). These studies have provided important insights into the origin and evolution of mycorrhizal associations in land plants, indicating that members of both fungal lineages might have engaged with the earliest embryophytes and played a key role in plant terrestrialisation. Major remaining knowledge gaps are the phylogenetic position of hornworts in the plant tree of life, whether their fungal associations are also mycorrhizal-like and whether hornworts, their ubiquitous cyanobacterial partners and varied fungal endophytes form tripartite symbiotic consortia, possibly representative of the ancestral symbiotic condition of land plants. Expanding genomic resources, including the development of Anthoceros agrestis as the first hornwort model species (Szövényi et al. 2015) hold much promise for answering these major evolutionary questions in the next decade.

Recent findings that the same Mucoromycotina symbionts of bryophytes are 'shared' by vascular plants (Hoysted et al. 2019), including angiosperms open up a new exciting chapter in mycorrhizal research. Whether the functional significance of symbioses with Mucoromycotina demonstrated in liverworts extend to the flowering plants is currently a key area of research with potentially major implications for our understanding of ecosystem functioning, both natural and agroecosystems. The recent development of methodologies for the isolation of Mucoromycotina symbionts and resynthesis of the symbiosis in vitro now provides a powerful experimental system for dissecting the role of these fungi across the land plant phylogeny and for determining their diagnostic structures and interfaces when colonising diverse host plants.

Our finding that the swollen rhizoids in Mylia anomala, reported here for the first time, contain Meliniomyces, rather than exclusively Rhizoscyphus ericae, and are cytologically distinct from those in all other ascomycete-containing liverworts fills the biggest gap in our knowledge of fungal associations across liverworts.

\section{References}

Adams, D.G. (2002) Cyanobacteria in symbiosis with hornworts and liverworts. In: Whitton, B.A. \& Potts, M. (Eds.) Ecology of cyanobacteria: their diversity in time and space. Kluwer Academic Publishers, Dordrecht, pp. 523-561. https://doi.org/10.1007/0-306-48005-0_7

Adams, D.G. \& Duggan, P.S. (2008) Cyanobacteria-bryophyte symbioses. Journal of Experimental Botany 59: 1047-1058. https://doi.org/10.1093/jxb/ern005

Azcón, R., Rubio, R. \& Barea, J.M. (1991) Selective interactions between different species of mycorrhizal fungi and Rhizobium meliloti strains, and their effects on growth, $\mathrm{N}_{2}$-fixation $\left({ }^{15} \mathrm{~N}\right)$ and nutrition of Medicago sativa L. New Phytologist 117: $339-404$. https://doi.org/10.1111/j.1469-8137.1991.tb00003.x

Berbee, M., James, T. \& Strullu-Derrien, C. (2017) Early diverging fungi: Diversity and impact at the dawn of terrestrial life. Annual Review of Microbiology 71: 41-59.

https://doi.org/10.1146/annurev-micro-030117-020324

Bergman, B., Johansson, C. \& Soderback E. (1992) The Nostoc-Gunnera symbiosis. New Phytologist 122: 379-400. https://doi.org/10.1111/j.1469-8137.1992.tb00067.x

Bidartondo, M.I., Bruns, T.D., Weiss, M., Sérgio, C. \& Read, D.J. (2003) Specialized cheating of the ectomycorrhizal symbiosis by an epiparasitic liverwort. Proceedings of the Royal Society B 270: 835-842.

https://doi.org/10.1098/rspb.2002.2299

Bidartondo, M.I. \& Duckett, J.G. (2010) Conservative ecological and evolutionary patterns in liverwort-fungal symbioses. Proceedings of the Royal Society B 277: 485-492.

https://doi.org/10.1098/rspb.2009.1458 
Bidartondo, M.I., Read, D.J., Trappe, J.M., Merckx, V., Ligrone, R. \& Duckett, J.G. (2011) The dawn of symbiosis between plants and fungi. Biology Letters 7: 574-577.

https://doi.org/10.1098/rsbl.2010.1203

Bonfante, P. \& Venice, F. (2020) Mucoromycota: going to the roots of plant-interacting fungi. Fungal Biology Reviews 34: 100-113. https://doi.org/10.1016/j.fbr.2019.12.003

Bowman, J.L., Araki, T., Arteaga-Vazquez, M.A., Berger, F., Dolan, L., Hasel-off, J., Ishizaki, K., Kyozuka, J., Lin, S.S., Nagasaki, H., Nakagami, H., Nakajima, K., Nakamura, Y., Ohashi-Ito, K., Sawa, S., Shimamura, M., Solano, R., Tsukaya, H., Ueda, T., Watanabe, Y., Yamato, K.T., Zachgo, S. \& Kohchi, T. (2016) The naming of names: guidelines for gene nomenclature in Marchantia. Plant Cell Physiology 57: 257-261.

https://doi.org/10.1093/pcp/pcv193

Bowman, J.L., Kohchi, T., Yamato, K.T., Jenkins, J., Shu, S., Ishizaki, K., Yamaoka, S., Nishihama, R., Nakamura, Y., Berger, F., Adam, C., Aki, S.S., Althoff, F., Araki, T., Arteaga-Vazquez, M.A., Balasubrmanian, S., Barry, K., Bauer, D., Boehm, C.R., Briginshaw, L., Caballero-Perez, J., Catarino, B., Chen, F., Chiyoda, S., Chovatia, M., Davies, K.M., Delmans, M., Demura, T., Dierschke, T., Dolan, L., Dorantes-Acosta, A.E., Eklund, D.M., Florent, S.N., Flores-Sandoval, E., Fujiyama, A., Fukuzawa, H., Galik, B., Grimanelli, D., Grimwood, J., Grossniklaus, U., Hamada, T., Haseloff, J., Hetherington, A.J., Higo, A., Hirakawa, Y., Hundley, H.N., Ikeda, Y., Inoue, K., Inoue, S.-I., Ishida, S., Jia, Q.-D., Kakita, M., Kanazawa, T., Kawai, Y., Kawashima, T., Kennedy, M., Kinose, K., Kinoshita, T., Kohara, Y., Koide, E., Komatsu, K., Kopischke, S., Kubo, M., Kyozuka, J., Lagercrantz, U., Lin, S.-S., Lindquist, E., Lipzen, A.M., Lu, C.-W., De Luna, E., Martienssen, R.A., Minamino, N., Mizutani, M., Mizutani, M., Mochizuki, N., Monte, I., Mosher, R., Nagasaki, H., Nakagami, H., Naramoto, S., Nishitani, K., Ohtani, M., Okamoto, T., Okumura, M., Phillips, J., Pollak, B., Reinders, A., Rövekamp, M., Sano, R., Sawa, S., Schmid, M.W., Shirakawa, M., Solano, R., Spunde, A., Suetsugu, N., Sugano, S., Sugiyama, A., Sun, R., Suzuki, Y., Takenaka, M., Takezawa, D., Tomogane, H., Tsuzuki, M., Ueda, T., Umeda, M., Ward, J.M., Watanabe, Y., Yazaki, K., Yokoyama, R., Yoshitake, Y., Yotsui, I., Zachgo, S. \& Schmutz, J. (2017) Insights into land plant evolution garnered from the Marchantia polymorpha genome. Cell 171: 287-304. https://doi.org/10.1016/j.cell.2017.09.030

Carafa, A., Duckett, J.G. \& Ligrone, R. (2003) Subterranean gametophytic axes in the primitive liverwort Haplomitrium harbour a unique type of endophytic association with aseptate fungi. New Phytologist 160: 185-197.

https://doi.org/10.1046/j.1469-8137.2003.00849.x

Chambers, S.M., Williams, P.G., Seppelt, R.D. \& Cairney, J.W.G. (1999) Molecular identification of Hymenoscyphus sp. from rhizoids of the leafy liverwort Cephaloziella exiliflora in Australia and Antarctica. Mycological Research 103: 286-288. https://doi.org/10.1017/S0953756298007217

Chang, Y., Desirò, A., Na, H., Sandor, L., Lipzen A., Clum, A., Barry, K., Grigoriev, I.V., Martin, F.M., Stajich, J.E., Smith, M.E., Bonito, G. \& Spatafora, J.W. (2019) Phylogenomics of Endogonaceae and evolution of mycorrhizas within Mucoromycota. New Phytologist 222: $511-525$.

https://doi.org/10.1111/nph.15613

Chang, Y., Wang, S., Sekimoto, S., Aerts, A.L., Choi, C., Clum, A., LaButti, K.M., Lindquist, E.A., Ngan, C.Y., Ohm, R.A., Salamov, A.A., Grigoriev, I.V., Spatafora, J.W. \& Berbee, M.L. (2015) Phylogenomic analyses indicate that early fungi evolved digesting cell walls of algal ancestors of land plants. Genome Biology and Evolution 7: 1590-1601.

https://doi.org/10.1093/gbe/evv090

Costa, J.-L., Paulstrud, P., Rikkinen, J. \& Lindblad, P. (2001) Genetic diversity of Nostoc symbionts endophytically associated with two bryophyte species. Applied and Environmental Microbiology 67: 4393-4396. https://doi.org/10.1128/aem.67.9.4393-4396.2001

Crandall-Stotler, B.R., Stotler, R.E. \& Long, D.G. (2009a) Morphology and classification of the Marchantiophyta. In: Goffinet, B. \& Shaw, A.J. (Eds.) Bryophyte Biology, 2nd edition. Cambridge University Press, Cambridge, pp. 1-54. https://doi.org/10.1017/CBO9780511754807.002

Crandall-Stotler, B., Stotler, R.E. \& Long, D.G. (2009b) Phylogeny and classification of the Marchantiophyta. Edinburgh Journal of Botany 66: 155-198.

https://doi.org/10.1017/S0960428609005393

Davis, E.C. (2004) Molecular phylogeny of leafy liverworts according to analysis of twelve genes. In: Hollowell, V. \& Magill, R. (Eds.) Molecular Systematics of Bryophytes, Missouri Botanical Gardens Press, St. Louis, pp. 61-86.

Delaux, P.M., Radhakrishnan, G.V., Jayaraman, D., Cheema, J., Malbreil, M., Volkening, J.D., Sekimoto, H., Nishiyama, T., Melkonian, M., Pokorny, L. \& Rothfels, C.J. (2015) Algal ancestor of land plants was preadapted for symbiosis. Proceedings of the National Academy of Sciences 112: 13390-13395.

https://doi.org/10.1073/pnas.1515426112

Delaux, P.M., Séjalon-Delmas, N., Bécard, G. \& Ané, J.M. (2013) Evolution of the plant-microbe symbiotic 'toolkit'. Trends in Plant 
Science 18: 298-304.

https://doi.org/10.1016/j.tplants.2013.01.008

De Roo, R.T., Hedderson, T.A. \& Söderström, L. (2007) Molecular insights into the phylogeny of the leafy liverwort family Lophoziaceae Cavers. Taxon 56: 301-314. https://doi.org/10.1002/tax.562005

de Sousa, F., Foster, P.G., Donoghue, P.C.J., Schneider, H. \& Cox, C.J. (2018) Nuclear protein phylogenies support the monophyly of the three bryophyte groups (Bryophyta Schimp.). New Phytologist 222: 565-575. https://doi.org/10.1111/nph.15587

Desirò, A., Duckett, J.G., Pressel, S., Villarreal, J.C. \& Bidartondo, M.I. (2013) Fungal symbioses in hornworts: a chequered history. Proceedings of the Royal Society of London B. 280: 20130207. https://doi.org/10.1098/rspb.2013.0207

Duckett, J.G., Carafa, A. \& Ligrone, R. (2006) A highly differentiated glomeromycotean association with the mucilage-secreting, primitive antipodean liverwort Treubia: clues to the origins of mycorrhizas. American Journal of Botany 93: 797-813. https://doi.org/10.3732/ajb.93.6.797

Duckett, J.G. \& Ligrone, R. (1992) A light and electron microscope study of the fungal endophytes in the sporophyte and gametophyte of Lycopodium cernuum L. with observations on the gametophyte-sporophyte junction. Canadian Journal of Botany 70: 58-72. https://doi.org/10.1139/b92-008

Duckett, J.G. \& Ligrone R. (2008a) A cytological analysis of basidiomycetous endophytes in New Zealand Aneuraceae (simple thalloid liverworts, Metzgeriidae); confirmation of the derived status of Verdoornia. Canadian Journal of Botany 86: 346-358. https://doi.org/10.1139/B08-004

Duckett, J.G. \& Ligrone, R. (2008b) Endophytic fungi in New Zealand liverworts. In: Engel, J.J. \& Glenny, D. (Eds.) A Flora of the Liverworts of New Zealand. Volume I. Missouri Botanical Garden Press, St. Louis. Monographs in Systematic Botany from the Missouri Botanical Garden 110, pp.48-56.

Duckett, J.G., Prasad, A.K.S.K., Davies, D.A. \& Walker, S. (1977) A cytological analysis of the Nostoc-bryophyte relationship. New Phytologist 79: 349-362. https://doi.org/10.1111/j.1469-8137.1977.tb02215.x

Duckett, J.G. \& Read, D.J. (1995) Ericoid mycorrhizas and rhizoid ascomycete associations in liverworts share the same mycobiont: isolation of the partners and resynthesis of the associations in vitro. New Phytologist 129: 439-447. https://doi.org/10.1111/j.1469-8137.1995.tb04315.x

Duckett, J.G., Renzaglia, K.S. \& Pell, K. (1991) A light and electron microscope study of rhizoid ascomycete associations and flagelliform axes in British hepatics with observations on the effects of the fungi on host morphology. New Phytologist 118: 233-257. https://doi.org/10.1111/j.1469-8137.1991.tb00975.x

Duckett, J.G., Russell, J. \& Ligrone, R. (2006b) Basidiomycetous endophytes in jungermannialean (leafy) liverworts have novel cytology and species-specific host ranges: a cytological and experimental study. Canadian Journal of Botany 84: 1075-1093. https://doi.org/10.1139/b06-073

Edwards, E., Cherns, L. \& Raven, J.A. (2015) Could land-based early photosynthesizing ecosystems have bioengineered the planet in mid-Palaeozoic times? Palaeontology 58: 803-837.

https://doi.org/10.1111/pala.12187

Engel, J.J. \& Braggins, J.E. (2005) Are Mylia and Trabacellula (Hepaticae) related? Unsuspected links revealed by cell wall morphology, with the transfer of Mylia anomala to a new genus (Leiomylia J.J. Engels \& Braggins) of Jungermanniaceae. Taxon 54: 665-680. https://doi.org/10.2307/25065423

Fehrer, J., Réblová, M., Bambasová, V. \& Vohník, M. (2019) The root-symbiotic Rhizoscyphus ericae aggregate and Hyaloscypha (Leotiomycetes) are congeneric: Phylogenetic and experimental evidence. Studies in Mycology 92: 195-225. https://doi.org/10.1016/j.simyco.2018.10.004

Field, K.J., Cameron, D.D., Leake, J.R., Tille, S., Bidartondo, M.I. \& Beerling, D.J. (2012) Contrasting arbuscular mycorrhizal responses of vascular and non-vascular plants to a simulated Palaeozoic $\mathrm{CO}_{2}$ decline. Nature Communications 3: 835. https://doi.org/10.1038/ncomms1831

Field, K.J., Bidartondo, M.I., Rimington, W.R., Hoysted, G., Beerling, D., Cameron, D., Duckett, J.G., Leake, J. \& Pressel, S. (2019) Functional complementarity of ancient plant-fungal mutualisms: contrasting nitrogen, phosphorus and carbon exchanges between Mucoromycotina and Glomeromycotina fungal symbionts of liverworts. New Phytologist 223: 908-921. https://doi.org/10.1111/nph.15819

Field, K.J. \& Pressel, S. (2018) Tansley Review - Unity in diversity: structural and functional insights into an ancient partnership between plants and fungi. New Phytologist 220: 996-1011.

https://doi.org/10.1111/nph.15158 
Field, K.J., Pressel, S., Duckett, J.G., Rimington, W.R. \& Bidartondo, M.I. (2015b) Symbiotic options for the conquest of land. Trends in Ecology and Evolution 30: 477-486. https://doi.org/10.1016/j.tree.2015.05.007

Field, K.J., Rimington, W.R., Bidartondo, M.I., Allinson, K.E., Beerling, D.J., Cameron, D.D., Duckett, J.G., Leake, J.R. \& Pressel, S. (2016) Functional analysis of liverworts in dual symbiosis with Glomeromycota and Mucoromycotina fungi under a simulated Palaeozoic $\mathrm{CO}_{2}$ decline. ISME Journal 10: 1514-1526.

https://doi.org/10.1038/ismej.2015.204

Field, K.J., Rimington, W.R., Bidartondo, M.I., Allison, K.E., Beerling, D.J., Cameron, D.D., Duckett, J.G., Leake, J.R. \& Pressel, S. (2015a) First evidence of mutualism between ancient plant lineages (Haplomitriopsida liverworts) and Mucoromycotina fungi and its response to simulated Palaeozoic changes in atmospheric $\mathrm{CO}_{2}$. New Phytologist 205: 743-756. https://doi.org/10.1111/nph.13024

Fisher, J.B. \& Vovides, A.P. (2004) Mycorrhizae are present in cycad roots. The Botanical Review 70: 16-23. [https://www.jstor.org/ stable/27571171]

Forrest, L.L. \& Crandall-Stotler, B.J. (2004) A phylogeny of the simple thalloid liverworts (Jungermanniopsida, Metzgeriidae) as inferred from five chloroplast genes. In: Goffinet, B., Hollowell, V. \& Magill, M.R. (Eds.) Molecular Systematics of Bryophytes. St. Louis, MO, USA: Missouri Botanical Garden, pp. 119-140.

Forrest, L.L., Davis, E.C., Long, D.G., Crandall-Stotler, B.J., Clark, A. \& Hollingsworth, M.L. (2006) Unravelling the evolutionary history of the liverworts (Marchantiophyta): multiple taxa, genomes and analyses. Bryologist 109: 303-334. https://doi.org/10.1639/0007-2745(2006)109[303:UTEHOT]2.0.CO;2

Frangedakis, E., Shimamura, M., Villarreal, J.C., Li, F-W.\& Tomaselli, M., Waller, M., Kakakibara, K., Renzaglia, K.S. \& Szövényi, P. (2021) The hornworts: morphology, evolution and development. New Phytologist 229: 735-754. https://doi.org/10.1111/nph.16874

Gottsche, C.M. (1843) Anatomisch-physiologische Untersuchungen über Haplomitrium hookeri N.v.E mit Vergleichung anderer Lebermoose. Novorum actorum Academia Caesareae Leopoldinae-Carolinae Germanicae Naturae Curiosorum 20: 267-398.

Grolle, R. (1963) Zwei Gattungen der Lophoziaceae neu für Afrika. Transactions of the British Bryological Society 4: 437-445. https://doi.org/10.1179/006813863804812363

Hambleton, S. \& Sigler, L. (2005) Meliniomyces, a new anamorph genus for root-associated fungi with phylogenetic affinities to Rhizoscyphus ericae (=Hymenoscyphus ericae), Leotiomycetes. Studies in Mycology 53: 1-27. https://doi.org/10.3114/sim.53.1.1

Harris, B.J., Harrison, C.J., Hetherington, A.M. \& Williams, T.A. (2020) Phylogenomic evidence for the monophyly of bryophytes and the reductive evolution of stomata. Current Biology 30: 2001-2012.e2. https://doi.org/10.1016/j.cub.2020.03.048

Hentschel, J., Wilson, R., Burghardt, M., Zündorf, H.-J., Schneider, H. \& Heinrichs, J. (2006) Reinstatement of Lophocoleaceae (Jungermanniopsida) based on chloroplast gene $r b c \mathrm{~L}$ data: exploring the importance of female involucres for the systematics of Jungermanniales. Plant Systematics and Evolution 258: 211-226. https://doi.org/10.1007/s00606-006-0408-y

Hentschel, J., Feldberg, K., Zündorf, H.-J., Hellwig, F.H., Schneider, H. \& Heinrichs, J. (2007) The systematic position of Pachyglossa and Clasmatocolea (Jungermanniopsida: Lophocoleaceae) inferred from nrDNA ITS sequences and morphology. Taxon 56: 11361142. https://doi.org/10.2307/25065908

He-Nygren, X., Ahonen, I., Juslen, A., Glenny, D. \& Piippo, S. (2004) Phylogeny of liverworts - beyond a leaf and a thallus. In: Goffinet, B., Hollowell, V. \& Magill, M.R. (Eds.) Molecular Systematics of Bryophytes. Missouri Botanical Garden, St. Louis, MO, USA, pp. $87-118$.

Hoysted, G.A., Bidartondo, M.I, Duckett, J.G., Pressel, S. \& Field, K.J. (2021) Phenology and function in lycopod-Mucoromycotina symbiosis. New Phytologist - Letter 229: 2389-2394. https://doi.org/10.1111/nph.17009

Hoysted, G.A., Jacob, A.S., Kowal, J., Giesemann, P., Bidartondo, M.I., Duckett, J.G., Gebauer, G., Rimington, W.R., Schornack, S., Pressel, S. \& Field, K.J. (2019) Mucoromycotina fine root endophyte fungi form nutritional mutualisms with vascular plants. Plant Physiology 181: 565-577. https://doi.org/10.1104/pp.19.00729

Humphreys, C.P., Franks, P.J., Rees, M., Bidartondo, M.I., Leake, J.R. \& Beerling, D.J. (2010) Mutualistic mycorrhiza-like symbiosis in the most ancient group of land plants. Nature Communications 1: 103. https://doi.org/10.1038/ncomms1105

Kottke, I., Beiter, A., Weiss, M., Haug, I., Oberwinkler, F. \& Nebel, M. (2003) Heterobasidiomycetes from symbiotic associations with 
hepatics: Jungermanniales have sebacinoid mycobionts while Aneura pinguis (Metzgeriales) is associated with a Tulasnella species. Mycological Research 107: 957-968.

https://doi.org/10.1017/s0953756203008141

Kottke, I. \& Nebel, M. (2005) The evolution of mycorrhiza-like associations in liverworts: an update. New Phytologist 167: 330-334. https://doi.org/10.1111/j.1469-8137.2005.01471.x

Kowal, J., Arrigoni, E., Jordi, S. \& Bidartondo, M.I. (2020) Prevalence and phenology of fine endophyte colonisation across populations of Lycopodiella inundata. Mycorrhiza 30: 577-587. http://dx.doi.org/10.1007/s00572-020-00979-3

Kowal, J., Pressel, S., Duckett, J.G., Bidartondo, M.I., Field, K.J. (2018) From rhizoids to roots? Experimental evidence of mutualism between liverworts and ascomycete fungi. Annals of Botany 121: 221-227. https://doi.org/10.1093/aob/mcx126

Koske, R.E., Gemma, J.N. \& Doyle, M.F. (1992) Mycorrhizal status of Gunnera petaloidea in Hawaii. Pacific Science 46: $480-483$.

Krause, C., Sigisfredo, G., Bauer, R. \& Nebel, M. (2011) Aneuraceae (Metzgeriales) and tulasnelloid fungi (Basidiomycota) - a model for early steps in fungal symbiosis. Fungal Biology 115: 839-851.

https://doi.org/10.1016/j.funbio.2011.06.013

Krings, M., Hass, H., Kerp, H., Taylor, T.N., Agerer, R. \& Dotzler, N. (2009) Endophytic cyanobacteria in a 400-million-yr-old land plant: A scenario for the origin of a symbiosis? Review of Paleobotany and Palynology 153: 62-69. https://doi.org/10.1016/j.revpalbo.2008.06.006

Krings, M., Taylor, T.N. \& Dotzler, N. (2012) Fungal endophytes as a driving force in land plant evolution. In: Southworth, D. (Ed.) Biocomplexity of Plant-Fungal Interactions. John Wiley \& Sons, pp. 5-28. https://doi.org/10.1002/9781118314364.ch1

Krings, M., Taylor, T.N., Hass, H., Kerp, H., Dotzler, N. \& Hermsen, E.J. (2007) Fungal endophytes in a 400-million-yr-old land plant: infection pathways, spatial distribution, and host responses. New Phytologist 175: 648-657. https://doi.org/10.1111/j.1469-8137.2007.02008.x

James, T.Y., Kauff, F., Schoch, C.L., Matheny, P.B., Hofstetter, V., Cox, C.J., Celio, G., Gueidan, C., Fraker, E., Miadlikowska, J., Lumbsch, H.T., Rauhut, A., Reeb, V., Arnold, A.E., Amtoft, A., Stajich, J.E., Hosaka, K., Sung, G.-H., Johnson, D., O’Rourke, B., Crockett, M., Binder, M., Curtis, J.M., Slot, J.C., Wang, Z., Wilson, A.W., Schüßler, A., Longcore, J.E., O’Donnell, K., Mozley-Standridge, S., Porter, D., Letcher, P.M., Powell, M.J., Taylor, J.W., White, M.M., Griffith, G.W., Davies, D.R., Humber, R.A., Morton, J.B., Sugiyama, J., Rossman, A.Y., Rogers, J.D., Pfister, D.H., Hewitt, D., Hansen, K., Hambleton, S., Shoemaker, R.A., Kohlmeyer, J., Volkmann-Kohlmeyer, B., Spotts, R.A., Serdani, M., Crous, P.W., Hughes, K.W., Matsuura, K., Langer, E., Langer, G., Untereiner, W.A., Lücking, R., Büdel, B., Geiser, D.M., Aptroot, A., Diederich, P., Schmitt, I., Schultz, M., Yahr, R., Hibbett, D.S., Lutzoni, F., McLaughlin, D.J., Spatafora, J.W. \& Vilgalys, R. (2006) Reconstructing the early evolution of Fungi using a six-gene phylogeny. Nature 443: 818-822.

https://doi.org/10.1038/nature05110

Jia, Y., Gray, V.M. \& Straker, C.J. (2004) The influence of Rhizobium and arbuscular mycorrhizal fungi on nitrogen and phosphorus accumulation by Vicia faba. Annals of Botany 94: 251-258.

https://doi.org/10.1093/aob/mch135

Lee, S-J., Kong, M., Harrison, P. \& Hijri, M. (2018) Conserved proteins of the RNA interference system in the arbuscular mycorrhizal fungus Rhizoglomus irregulare provide new insight into the evolutionary history of Glomeromycota. Genome Biology and Evolution 10: 328-343. https://doi.org/10.1093/gbe/evy002

Lenton, T.M. \& Daines, S.J. (2017) Matworld - the biogeochemical effects of early life on land. New Phytologist 215: 531-537. https://doi.org/10.1111/nph.14338

Li, F-W., Nishiyama, T., Waller, M., Frangedakis, E., Keller, J., Li, Z., Fernandez-Pozo, N., Barker, M.S., Bennett, T., Blázquez, M.A., Cheng, S., Cuming, A.C., de Vries, J., de Vries, S., Delaux, P.-M., Diop, I.S., Harrison, C.J., Hauser, D., Hernández-García, J., Kirbis, A., Meeks, J.C., Monte, I., Mutte, S.K., Neubauer, A., Quandt, D., Robison, T., Shimamura, M., Rensing, S.A., Villarreal, J.C., Weijers, D., Wicke, S., Wong, G.K.-S., Sakakibara, K. \& Szövényi, P. (2020) Anthoceros genomes illuminate the origin of land plants and the unique biology of hornworts. Nature Plants 6: 259-272.

https://doi.org/10.1038/s41477-020-0618-2

Ligrone, R. (1988) Ultrastructural of a fungal endophyte in Phaeoceros laevis (L.) Prosk. (Anthocerotophyta). Botanical Gazette 149: 92-100. [https://www.jstor.org/stable/2995425]

Ligrone, R., Carafa, A., Lumini, E., Bonfante, P., Biancotto, V. \& Duckett, J.G. (2007) Glomeromycotean associations in liverworts: a molecular, cytological and taxonomical survey. American Journal of Botany 94: 1756-1777.

https://doi.org/10.3732/ajb.94.11.1756 
Lindblad, P. \& Bergman, B. (2018) The cycad-cyanobacterial symbiosis. In: Rai, A.N. (Ed.) CRC handbook of symbiotic cyanobacteria. CRC Press, Boca Raton, FL, USA, 137-159.

Margulis, L. \& Chapman, M.J. (1998) Endosymbioses: cyclical and permanent evolution. Trends in Microbiology 6: 342-345. https://doi.org/10.1016/S0966-842X(98)01325-0

Nebel, M., Kreier, H.-P., Preußing, M. \& Weiss, M.A. (2004) Symbiotic fungal associations with liverworts are the possible ancestors of mycorrhizae. In: Agerer, R., Piepenbring, H. \& Blanz, P. (Eds.) Frontiers in Basidiomycote Mycology, HIW-Verlag, Ecking, Germany, pp. 339-360.

Newsham, K.K. \& Bridge, P.D. (2010) Sebacinales are associates of the leafy liverwort Lophozia excisa in the southern maritime Antarctic. Mycorrhiza 20: 307-313. https://doi.org/10.1007/s00572-009-0283-9

Oldroyd, G.E. (2013) Speak, friend, and enter: signalling systems that promote beneficial symbiotic associations in plants. Nature Reviews Microbiology 11: 252-263. https://doi.org/10.1038/nrmicro2990

Orchard, S., Hilton, S., Bending, G.D., Dickie, I.A., Standish, R.J., Gleeson, D.B., Jeffery, R.P., Powell, J.R., Walker, C., Bass, D., Monk, J., Simonin, A. \& Ryan, M.H. (2017a) Fine endophytes (Glomus tenue) are related to Mucoromycotina, not Glomeromycotina. New Phytologist 213: 481-486. https://doi.org/10.1111/nph.14268

Orchard, S., Standish, R.J., Dickie, I.A., Renton, M., Walker, C., Moot, D. \& Ryan, M.H. (2017b) Fine root endophytes under scrutiny: a review of the literature on arbuscule-producing fungi recently suggested to belong to the Mucoromycotina. Mycorrhiza 27: 619638. https://doi.org/10.1007/s00572-017-0782-z

Paton, J.A. (1999) The Liverwort Flora of the British Isles. Brill, Leiden.

Perotto, S., Daghino, S. \& Martino, E. (2018) Ericoid mycorrhizal fungi and their genomes: another side to mycorrhizal symbiosis? New Phytologist 220: 1141-1147.

https://doi.org/10.1111/nph.15218

Pirozynski, K.A. \& Malloch, D.W. (1975) The origin of land plants: a matter of mycotrophism. Biosystems 6: $153-164$. https://doi.org/10.1016/0303-2647(75)90023-4

Pressel, S., Bidartondo, M.I., Field, K.J., Rimington, W.R. \& Duckett, J.G. (2016) Pteridophyte fungal associations: Current knowledge and future perspectives. Journal of Systematics and Evolution 54: 666-678. https://doi.org/10.1111/jse.12227

Pressel, S., Bidartondo, M.I., Ligrone, R. \& Duckett, J.G. (2010) Fungal symbioses in bryophytes: New insights in the twenty first century. Phytotaxa 9: 238-253.

https://doi.org/10.11646/phytotaxa.9.1.13

Pressel, S., Davis, E.C., Ligrone, R. \& Duckett, J.G. (2008a) An ascomycetous endophyte induces branching and septation of the rhizoids in the leafy liverwort family the Schistochilaceae (Jungermanniidae, Hepaticopsida). American Journal of Botany 95: 531-541. https://doi.org/10.3732/ajb.2007171

Pressel, S., Ligrone, R. \& Duckett, J.G. (2008b) The ascomycete Rhizoscyphus ericae elicits a range of host responses in the rhizoids of leafy liverworts; an experimental and cytological analysis. Fieldiana 47: 59-72. https://doi.org/10.3158/0015-0746-47.1.59

Pressel, S., P'ng, K.M.Y. \& Duckett, J.G. (2011) An ultrastructural study of the liverwort Mizutania riccardioides Furuki et Iwaksuki: new insights into its systematic affinities and unique surface ornamentation. Bryologist 114: 38-51.

Preußing, M., Nebel, M., Oberwinkler, M. \& Weiss, M. (2010) Diverging diversity patterns in Tulasnella (Basidiomycota, Tulasnellales) mycobionts of Aneura pinguis (Marchantiophyta, Metzgeriales) from Europe and Ecuador. Mycorrhiza 20: 147-159. https://doi.org/10.1007/s00572-009-0275-9

Puttick, M.N., Morris, J.L., Williams, T.A., Cox, C.J., Edwards, D., Kenrick, P., Pressel, S., Wellman, C.H., Schneider, H., Pisani, D. \& Donoghue, P.C.J. (2018) The interrelationships of land plants and the nature of the ancestral embryophyte. Current Biology 28 : 733-745.e2. https://doi.org/10.1016/j.cub.2018.01.063

Qiu, Y-L., Li, L., Wang, B., Chen, Z., Knoop, V., Groth-Malonek, M., Dombrovska, O., Lee, J., Kent, L., Rest, J., Estabrook, J.F., Hendry, T.A., Taylor, D.W., Testa, C.M., Ambros, M., Crandall-Stotler, B., Duff, R.J., Stech, M., Frey, W., Quandt, D. \& Davis, C.C. (2006) The deepest divergences in land plants inferred from phylogenomic evidence. Proceedings of the National Academy of Sciences, USA 103: 15511-15516. https://doi.org/10.1073/pnas.0603335103

Read, D.J., Duckett, J.G., Francis, R., Ligrone, R. \& Russell, A. (2000) Symbiotic fungal associations in 'lower' land plants. Philosophical 
Transactions of the Royal Society B. 355: 815-832. [https://www.jstor.org/stable/3066807]

Read, D.J., Leake, J.R. \& Perez-Moreno, J. (2004) Mycorrhizal fungi as drivers of ecosystem processes in heathland and boreal forest biomes. Canadian Journal of Botany 82: 1243-1263.

https://doi.org/10.1139/b04-123

Remy, W., Taylor, T.N., Hass, H. \& Kerp, H. (1994) Four hundred-million-year-old vesicular arbuscular mycorrhizae. Proceedings of the National Academy of Sciences, USA 91: 11841-11843.

https://doi.org/10.1073/pnas.91.25.11841

Renzaglia, K.S., Villarreal, J.C. \& Duff, RJ. (2009) New insights into morphology, anatomy, and systematics of hornworts. In: Goffinet, B. \& Shaw, A.J. (Eds.) Bryophyte Biology. Cambridge University Press, Cambridge, pp. 139-171.

https://doi.org/10.1017/CBO9780511754807.004

Rikkinen, J. (2017) Cyanobacteria in terrestrial symbiotic systems. In: Hallenbeck, P. (ed.) Modern Topics in the Phototrophic Prokaryotes, Springer, Cham, pp. 243-294.

https://doi.org/ 10.1007/978-3-319-46261-5_8

Rimington, W.R., Duckett, J.G., Field, K.J., Bidartondo, M.I. \& Pressel, S. (2020) The distribution and evolution of fungal symbioses in ancient lineages of land plants. Mycorrhiza 30: 23-49.

https://doi.org/10.1007/s00572-020-00938-y

Rimington, W.R., Pressel, S., Duckett, J.G., Field, K.J. \& Bidartondo, M.I. (2019) Evolution and networks in ancient and widespread symbioses between Mucoromycotina and liverworts. Mycorrhiza 29: 551-565.

https://doi.org/10.1007/s00572-019-00918-x

Rimington, W.R., Pressel, S., Duckett, J.G., Field, K.J., Read, D.J. \& Bidartondo, M.I. (2018) Ancient plants with ancient fungi: liverworts associate with early-diverging arbuscular mycorrhizal fungi. Proceedings of the Royal Society B: Biological Sciences 285: 20181600 .

https://doi.org/10.1098/rspb.2018.1600

Russell, J. \& Bulman, S. (2005) The liverwort Marchantia foliacea forms a specialized symbiosis with arbuscular mycorrhizal fungi in the genus Glomus. New Phytologist 165: 567-579.

https://doi.org/10.1111/j.1469-8137.2004.01251.x

Schmid, D. \& Oberwinkler, F. (1993) Mycorrhiza-like interaction between the achlorophyllous gametophyte of Lycopodium clavatum L. and its fungal endophyte studied by light and electron microscopy. New Phytologist 124: 69-81. https://doi.org/10.1111/j.1469-8137.1993.tb03798.x

Schüßler, A. (2000) Glomus claroideum forms an arbuscular mycorrhiza-like symbiosis with the hornwort Anthoceros punctatus. Mycorrhiza 10: 15-21. https://doi.org/10.1007/s005720050282

Schüßler, A. (2002) Molecular phylogeny, taxonomy, and evolution of Geosiphon pyriformis and arbuscular mycorrhizal fungi. Plant and Soil 244: 75-83. https://doi.org/10.1023/A:1020238728910

Schüßler, A. (2012) 5. The Geosiphon-Nostoc endosymbiosis and its role as a model for arbuscular mycorrhiza research. In: Hock, B. (Ed.) Fungal Associations. The Mycota (A Comprehensive Treatise on Fungi as Experimental Systems for Basic and Applied Research), vol. 9. Springer, Berlin, Heidelberg, pp. 77-91. https://doi.org/10.1007/978-3-642-30826-0_5

Schüßler, A., Schwarzott, D. \& Walker, C. (2001) A new fungal phylum, the Glomeromycota: phylogeny and evolution. Mycological Research 105: 1413-1421. https://doi.org/10.1017/S0953756201005196

Schüßler, A. \& Walker, C. (2011) Evolution of the 'plant-symbiotic' fungal phylum, Glomeromycota. In: Pöggeler, S. \& Wöstemeyer (Eds.) The Mycota XIV. Evolution of Fungi and Fungal-Like Organisms. Springer, Berlin, pp. 163-185. https://doi.org/10.1007/978-3-642-19974-5_7

Schuster, R.M. (1966) The Hepaticae and Anthocerotae of North America. Volume 1. Colombia University Press, New York.

Schuster, R.M. (1969) The Hepaticae and Anthocerotae of North America. II. Columbia University Press, New York.

Shaw, B., Crandall-Stotler, B., Váňa, J., Stotler, R.E., von Konrat, M., Engel, J.J., Davis, E.C., Long, D.G., Sova, P. \& Shaw, A.J. (2015) Phylogenetic relationships and morphological evolution in a major clade of leafy liverworts (phylum Marchantiophyta, order Jungermanniales): suborder Jungermanniineae. Systematic Botany 40: 27-45.

https://doi.org/10.1600/036364415X68314

Selosse, M.-A. (2005) Are liverworts imitating mycorrhizas? New Phytologist 165: 345-349.

Smith, F.A. \& Smith, S.E. (1997) Structural diversity in (vesicular)-arbuscular mycorrhizal symbioses. New Phytologist 137: $373-388$. https://doi.org/10.1046/j.1469-8137.1997.00848.x 
Spatafora, J.W., Chang, Y., Benny, G.L., Lazarus, K., Smith, M.E., Berbee, M.L., Bonito, G., Corradi, N., Grigoriev, I., Gryganskyi, A. \& James, T.Y. (2016) A phylum-level phylogenetic classification of zygomycete fungi based on genome-scale data. Mycologia 108: $1028-1046$. https://doi.org/10.3852/16-042

Sousa, F., Civáň, P., Brazão, J., Foster, P.G. \& Cox, C.J. (2020) The mitochondrial phylogeny of land plants shows support for Setaphyta under composition-heterogeneous substitution models. PeerJ 8: e8995. http://doi.org/10.717/peerj.8995

Söderstrom, L., Hagborg, A., von Konrat, M., Bartholomew-Began, S., Bell, D., Briscoe, L., Brown, E., Cargill, D.C., Costa, D.P., Crandall-Stotler, B.J., Cooper, E.D., Dauphin, G., Engel, J., Feldberg, K., Glenny, D., Gradstein, S.R., He, X.-L., Heinrichs, J., Hentschel, J., Ilkiu-Borges, A.L., Katagiri, T., Konstantinova, N.A., Larraín, J., Long, D., Nebel, M., Pócs, T., Puche, F., ReinerDrehwald, E., Renner, M., Sass-Gyarmati, A., Schäfer-Verwimp, A., Segarra-Moragues, J.G., Stotler, R.E., Sukkharak, P., Thiers, B., Uribe, J., Váňa, J., Villarreal, J., Wigginton, M., Zhang, L. \& Zhu, R.-L. (2016) World checklist of hornworts and liverworts. Phytokeys 59: 1-828. https://doi.org/10.3897/phytokeys.59.6261

Stahl, M. (1949) Die Mycorrhiza der Lebermoose mit besonderer Berücksichtigung der thallosen Formen. Planta 37: 103-148. [https:// www.jstor.org/stable/23359038]

Strullu-Derrien, C., Kenrick, P., Pressel, S., Duckett, J.G., Rioult, J.P. \& Strullu, D.G. (2014) Fungal associations in Horneophyton ligneri from the Rhynie Chert (c. 407 million ear old) closely resemble those in extant lower land plants: novel insights into ancestral plant-fungus symbioses. New Phytologist 203: 964-979. https://doi.org/10.1111/nph.12805

Szövényi, P. (2016) The genome of the model species Anthoceros agrestis. In: Rensing, SA. (Ed.) Genomes and Evolution of Charophytes, Bryophytes, Lycophytes and Ferns. Elsevier, Amsterdam, pp.189-211. https://doi.org/10.1016/bs.abr.2015.12.001

Szövényi, P., Frangedakis, E., Ricca, M., Quandt, D., Wicke, S. \& Langdale, J.A. (2015) Establishment of Anthoceros agrestis as a model species for studying the biology of hornworts. BMC Plant Biology 15: 98. https://doi.org/10.1186/s12870-015-0481-x

Taylor, T.N., Remy, W., Hass, H. \& Kerp, H. (1995) Fossil arbuscular mycorrhizae from the Early Devonian. Mycologia 87: 560-573. https://doi.org/10.2307/3760776

Tedersoo, L., Pärtel, K., Jairus, T., Gates, G., Poldmaa, K. \& Tamm, H. (2009) Ascomycetes associated with ectomycorrhizas: molecular diversity and ecology with particular reference to the Helotiales. Environmental Microbiology 11: 3166-3178. https://doi.org/10.1111/j.1462-2920.2009.02020.x

Uehling, J., Gryganskyi, A., Hameed, K., Tschaplinski, T., Misztal, P.K., Wu, S., Desirò, A., Vande Pol, N., Du, Z., Zienkiewicz, A. \& Zienkiewicz, K. (2017) Comparative genomics of Mortierella elongata and its bacterial endosymbiont Mycoavidus cysteinexigens. Environmental Microbiology 19: 2964-2983. https://doi.org/10.1111/1462-2920.13669

Upson, R., Read, D.J. \& Newsham, K.K. (2007) Widespread association between the ericoid mycorrhizal fungus Rhizoscyphus ericae and a leafy liverwort in the maritime and sub-Antarctic. New Phytologist 176: 460-471. https://doi.org/10.1111/j.1469-8137.2007.02178.x

Villarreal, J.C. \& Renner, S.S. (2012) Hornwort pyrenoids, carbon-concentrating structures, evolved and were lost at least five times during the last 100 million years. Proceedings of the National Academy of Sciences, USA 109: 18873-18878. https://doi.org/10.1073/pnas.1213498109

Villarreal, J.C. \& Renzaglia, KS. (2006) Structure and development of Nostoc strands in Leiosporoceros dussii (Anthocerotophyta): a novel symbiosis in land plants. American Journal of Botany 93: 693-705. https://doi.org/10.3732/ajb.93.5.693

Villarreal-Ruiz, L., Anderson, I.C. \& Alexander, I.J. (2004) Interactions between an isolate from the Hymenoscyphus ericae aggregate and roots of Pinus and Vaccinium. New Phytologist 164: 183-192. https://doi.org/10.1111/j.1469-8137.2004.01167.x

Walker, C., Gollotte, A. \& Redecker, D. (2018) A new genus, Planticonsortium (Mucoromycotina), and new combination (P. tenue), for the fine root endophyte, Glomus tenue (basionym Rhizophagus tenuis). Mycorrhiza 28: 213-219. https://doi.org/10.1007/s00572-017-0815-7

Wang, B. \& Qiu, Y.L. (2006) Phylogenetic distribution and evolution of mycorrhizas in land plants. Mycorrhiza 16: $299-363$. https://doi.org/10.1007/s00572-005-0033-6

Wang, B., Yeun, L.H., Xue, J.Y., Liu, Y., Ané, J.M. \& Qiu, Y.L. (2010) Presence of three mycorrhizal genes in the common ancestor of land plants suggests a key role of mycorrhizas in the colonization of land by plants. New Phytologist 186: 514-525. 
https://doi.org/10.1111/j.1469-8137.2009.03137.x

Warshan, D., Liaimer, A., Pederson, E., Kim, S-Y., Shapiro, N., Woyke, T., Altermark, B., Pawloski, K., Weyman, P.D., Dupont, C.L. \& Rasmussen, U. (2018) Genomic changes associated with the evolutionary transitions of Nostoc to a plant symbiont. Molecular Biology and Evolution 35: 1160-1175.

https://doi.org/10.1093/molbev/msy029

Wickett, N.J., Mirarab, S., Nguyen, N., Warnow, T., Carpenter, E., Matasci, N., Ayyampalayam, S., Barker, M.S., Burleigh, J.G., Gitzendanner, M.A., Ruhfel, B.R., Wafula, E., Der, J.P., Graham, S.W., Mathews, S., Melkonian, M., Soltis, D.E., Soltis, P.S., Miles, N.W., Rothfels, C.J., Pokorny, L., Shaw, A.J., DeGironimo, L., Stevenson, D.W., Surek, B., Villarreal, J.C., Roure, B., Philippe, H., dePamphilis, C.W., Chen, T., Deyholos, M.K., Baucom, R.S., Kutchan, T.M., Augustin, M.M., Wang, J., Zhang, Y., Tian, Z., Yan, Z., Wu, X., Sun, X., Wong, G.K.-S. \& Leebens-Mack, J. (2014) Phylotranscriptomic analysis of the origin and early diversification of land plants. Proceedings of the National Academy of Sciences, USA 111: E4859-E4868.

https://doi.org/10.1073/pnas.1323926111

Whitton, B.A. (1993) Cyanobacteria and Azolla. In: Jones, D.G. (Ed.) Exploitation of microorganisms. Springer, Dordrecht, pp. 137167.

https://doi.org/10.1007/978-94-011-1532-2_6

Xavier, L.J.C. \& Germida, J.J. (2002) Response of lentil under controlled conditions to co-inoculation with arbuscular mycorrhizal fungi and rhizobia varying in efficacy. Soil Biology \& Biochemistry 34: 181-188.

https://doi.org/10.1016/S0038-0717(01)00165-1

Xavier, L.J.C. \& Germida, J.J. (2003) Selective interactions between arbuscular mycorrhizal fungi and Rhizobium leguminosarum bv. viceae enhance pea yield and nutrition. Biology and Fertility of Soils 37: 262-267.

https://doi.org/10.1007/s00374-003-0605-6 